\title{
Neurotropic Properties of Pseudorabies Virus: Uptake and Transneuronal Passage in the Rat Central Nervous System
}

\author{
J. P. Card, ${ }^{1}$ L. Rinaman, ${ }^{2, a}$ J. S. Schwaber, ${ }^{1}$ R. R. Miselis, ${ }^{2}$ M. E. Whealy, ${ }^{1}$ A. K. Robbins, ${ }^{1}$ and L. W. Enquist ${ }^{1}$ \\ 'E. I. Dupont de Nemours \& Co., Wilmington, Delaware 19898, and Institute of Neurological Sciences, Department of \\ Animal Biology, University of Pennsylvania, Philadelphia, Pennsylvania 19106
}

\begin{abstract}
Uptake, replication, and transneuronal passage of a swine neurotropic herpesvirus (pseudorabies virus, PRV) was evaluated in the rat CNS. PRV was localized in neural circuits innervating the tongue, stomach, esophagus, and eye with light microscopic immunohistochemistry. In each instance, the distribution of PRV-immunoreactive neurons was entirely consistent with that observed following injection of cholera toxin-horseradish peroxidase conjugate (CT-HRP). Injections of the tongue resulted in retrograde transport of PRV and CT-HRP to hypoglossal motor neurons, while preganglionic neurons in the dorsal motor vagal nucleus or somatic motor neurons in the nucleus ambiguus were labeled following injections of the stomach or esophagus, respectively. At longer times after infection, viral antigens were found in astrocytes adjacent to infected neurons and their efferent axons and second-order neuron labeling became apparent. The distribution of second-order neurons was also entirely dependent upon the site of PRV injection. Following tongue injection, second-order neurons were observed in the trigeminal complex, the brain-stem tegmentum and in monoaminergic cell groups. Injection of the stomach or esophagus led to second-order neuron labeling confined to distinct subdivisions of the neucleus of the solitary tract and monoaminergic cell groups. Comparative quantitative analysis of the number of PRV immunoreactive neurons present in the diencephalon and brain stem following injection of virus into both the eye and stomach musculature of the same animal demonstrated that retrograde transport of PRV from the viscera was more efficient and occurred at a much faster rate than anterograde transport of virus. These data demonstrate projection-specific transport of PRV in the nervous system and provide further insight into the means through which this neurotropic virus infects the nervous system.
\end{abstract}

The affinity of herpesviruses for the peripherally projecting processes of neurons in the mammalian CNS is well established (see Wittmann and Rziha, 1989, and Stroop and Baringer, 1989, for reviews). Goodpasture and Teague (1923) initially suggested

\footnotetext{
Received Oct. 10, 1989; revised Dec. 26, 1989; accepted Jan. 23, 1990.

This work was supported by funds provided by the DuPont company and NIH grant GM 27739 to R.R.M. We acknowledge the expert technical assistance of Raymond Meade, Timothy Hancock, and Claudia Williams.

Correspondence should be addressed to Dr. J. Patrick Card, Virology Disease Group, Central Research and Development Department, Experimental Station, E228/138, Wilmington, DE 19880-0228.

a Present Address: Medical College of Pennsylvania, Department of Anatomy, 3200 Henry Avenue, Philadelphia, PA 19129.

Copyright (C) 1990 Society for Neuroscience $0270-6474 / 90 / 061974-21 \$ 02.00 / 0$
}

that virions are taken up by nerve endings and transported to neuronal perikarya via retrograde axonal transport. In the same report, neuropathological changes in the geniculate body following injection of herpes simplex virus into the rabbit eye led these investigators to the conclusion that virions are also transported via anterograde axonal transport. These observations have subsequently been confirmed in numerous investigations employing different herpesviruses and a number of different species of experimental animals (Wildy, 1967; Baringer and Griffith, 1970; Kristensson, 1970; Cook and Stevens, 1973; McCracken et al., 1973; Kristensson et al., 1974, 1978, 1982; Bak et al., 1977, 1978; Dolivo et al., 1978; Townsend and Baringer, 1978; Vahlne et al., 1978, 1980; Martin and Dolivo, 1983). Nevertheless, very little is known about the mechanisms which direct viral uptake, transport, and replication within the nervous system.

A number of recent investigations have presented evidence that herpesviruses pass through synaptically linked circuits of neurons following either peripheral or central injection. In 1982 , Kristensson and colleagues demonstrated remarkable selectivity in the neuronal transport of herpes simplex virus type 1 (HSV1) injected into the mouse snout. This experimental paradigm resulted in viral replication within neurons of the trigeminal ganglia, the main scnsory and spinal tract trigeminal nuclei, and monoaminergic neurons of the brain stem. The progressive appearance of virus within these cell groups with increasing time, along with the fact that the neurons are known to be synaptically linked, strongly suggested that virions were passing from neuron to neuron through sites of synaptic contact. This conclusion has been supported in a number of studies which reported viral replication confined to functionally linked circuits of CNS neurons following both peripheral and central injections of virus (Bak et al., 1978; Martin and Dolivo, 1983; Ugolini et al., 1987, 1989; Norgren and Lehman, 1989; Rouiller et al., 1989; Strack et al., 1989). However, it has not yet been firmly established that second- and third-order neuron labeling results from transsynaptic transport of virions rather than from nonspecific uptake of virions released into the extracellular space.

The present study was conducted to define animal models of neurotropic viral interaction in order to identify sites for therapeutic intervention in the course of infection. Uptake, transport, and replication of a neurotropic swine herpesvirus (pseudorabies virus; PRV) in 4 distinct neural circuits has been systematically evaluated in the rat CNS following peripheral injection of the virus. The data provide strong evidence for specific transneuronal transport of the virus and also indicate that the rate of retrograde transport exceeds the rate of anterograde axonal transport. In addition, the unique and reprodu- 
cible patterns of central viral replication provide an excellent framework for examining the mechanisms which direct uptake, replication, and transport of this neurotropic virus.

\section{Materials and Methods}

\section{Animals}

Adult male Sprague-Dawley rats (220-260 gm body weight at death) were used in this investigation. The animals were maintained in a standardized environment throughout the course of the experiment (14 hr light; light on at 0600 ) with food and water freely available. Procedures for the maintenance and use of experimental animals conformed to the regulations detailed in the NIH Guide for the Care and Use of Laboratory Animals. In addition, all experimental protocols were reviewed and approved by the local Animal Welfare Committee prior to their implementation. Chloropentane $(3.2 \mathrm{ml} / \mathrm{kg}$ body weight; Fort Dodge Laboratories) or sodium pentobarbitol $(40 \mathrm{mg} / \mathrm{kg}$ ) was injected intraperitoneally prior to all experimental manipulations.

\section{Characteristics of $P R V$}

PRV is an alphaherpesvirus which belongs to the herpesviridae family and is related to herpes simplex virus types 1 and 2 . It is a large, enveloped DNA virus that, like all herpesviruses, is thought to acquirc its envelope by budding from the nucleus rather than the plasma membrane. Wittmann and Rziha (1989) have recently published a comprehensive review of literature describing the history, infectivity, and experimental analysis of the virus. The following aspects of their review are pertinent to the present investigation. Although PRV has a broad host range and is endemic to many parts of the world, there is no evidence that PRV can productively infect humans. Certainly, no cases of accidental laboratory infection have ever been documented. The pig is the primary host, with younger animals more vulnerable to infection. Among laboratory animals, the rabbit is most sensitive to infection. However, some primates (rhesus monkeys, macaques, and Grivet monkeys) and rodents are susceptible to experimental infection. Intracerebral, intranasal, subcutaneous, and intramuscular application of PRV have all been demonstrated to lead to infection of laboratory animals.

PRV is quite sensitive to variations in temperature and is inactivated by a number of chemical reagents. It is inactivated at $60^{\circ} \mathrm{C}$ within $30-$ $60 \mathrm{~min}$, at $70^{\circ} \mathrm{C}$ within $10-15 \mathrm{~min}$, at $80^{\circ} \mathrm{C}$ within $3 \mathrm{~min}$, and at $100^{\circ} \mathrm{C}$ within $1 \mathrm{~min}$. Additionally, it is inactivated within 12 weeks at temperatures from -18 to $-25^{\circ} \mathrm{C}$. Aldehydes effectively inactivate the virus at low concentrations; 3\% glutaraldehyde inactivates PRV within 10 min, and $4 \%$ formaldehyde reduces infectivity by $60 \%$ within 5 min and completely after $3 \mathrm{hr}$. Alcohols, chloroform, and Clorox effectively inactivate the virus at room temperature.

\section{Preparation of $P R V$}

PRV was prepared in a Biosafety level 2 (BSL-2) containment facility. The Becker strain of PRV was grown in porcine kidney fibroblasts (PK 15 cells). Virus-infected cells were scraped into the media, freeze-thawed, sonicated, cleared of cellular debris by centrifugation, and stored at $-70^{\circ} \mathrm{C}$ in $200 \mu \mathrm{l}$ aliquots. Determination of the number of plaqueforming units (pfu) in each viral stock revealed an average of $1 \times 10^{8}$ $\mathrm{pfu} / \mathrm{ml}$. Fresh aliquots of virus were thawed immediately prior to injection.

\section{Antisera}

The antisera used in these studies included a rabbit polyvalent antiserum generated against the entire virion (Rb134) and a goat monospecific, polyvalent antiserum ( 282 ) gencrated against gIII, the major envelope glycoprotein of PRV (Robbins et al., 1986; Ryan et al., 1987). Rb134 was prepared by injecting rabbits with acetone-inactivated virus; this antiserum binds to envelope and capsid antigens of PRV. The g282 antiserum recognizes native and denatured forms of gIII in both the glycosylated and nonglycosylated states.

\section{Cholera toxin-horseradish peroxidase conjugate (CT-HRP)}

The pattern of neuronal labeling resulting from peripheral injection of PRV was compared to that observed following injection of CT-HRP according to the same parameters. CT-HRP was chosen for this comparison because it is a highly specific neuronal tracer that is effectively transported in both anterograde and retrograde directions (Trojanowski et al., 1981, 1982). The conjugate was prepared in our laboratory as described previously (Shapiro and Miselis, 1985a) and diluted to $0.25 \%$ (determined by Lowry assay). Aliquots $(5-10 \mu \mathrm{l})$ of CT-HRP were stored at $-20^{\circ} \mathrm{C}$ and thawed immediately prior to injection.

\section{Experimental procedures}

\section{Virus injections}

Use of PRV in our laboratory was carefully controlled. Experimental protocols involving use of the virus were approved by the Animal Welfare Committee, which is subject to the rules and regulations of the American Association for Accreditation of Laboratory Animal Care and those stipulated in the Animal Welfare Act (Public Law 99-198). Use of PRV was restricted to a BSL-2 containment facility dedicated exclusively to these experiments. The conduct of experiments in this facility conformed to BSL-2 regulations detailed in Health and Human Services Publication No. 88-8395 (Biosafety in Microbiological and Biomedical I.aboratories). All animals included in the studies were confined to the BSL-2 laboratory throughout the course of the analysis, and each experiment was terminated by transcardiac infusion of buffered aldehyde solutions through deeply anesthetized animals (details provided in subsequent sections). Unused tissues were incinerated and surgical instruments were decontaminated with Clorox.

Anesthetized animals received injections of $1-10 \mu \mathrm{l}\left(1 \times 10^{5}-1 \times 10^{\circ}\right.$ $\mathrm{pfu} / \mu \mathrm{l}$ ) of PRV as detailed in Table 1 . The site and mode of injection was standardized in all cases.

Tongue. Tongue injections were confined to the ventrolateral musculature, midway along the longitudinal axis. In the majority of virusinjected animals, a single $1 \mu$ injection of PRV was made unilaterally. However, in 2 cases, four $1 \mu \mathrm{l}$ injections of virus were made along the lateral aspect of each side of the tongue. In every instance, the needle was inserted approximately $2 \mathrm{~mm}$ into the lateral surface and pierced the genioglossis and adjacent musculature.

Stomach. One group of animals received a single injection of PRV $(1-8 \mu \mathrm{l})$ into the ventral musculature of the corpus (exposed via laparotomy), just below the gastroesophageal junction. A second experimental group received multiple (2-10) $1 \mu 1$ injections of PRV across the ventral surface of the corpus and antrum of the stomach. Four of these animals were subjected to cervical vagotomy prior to injection of PRV. In these cases, the cervical portion of the right or left vagus nerve was exposed and approximately $5 \mathrm{~mm}$ of the nerve just below the nodose ganglion was removed. Injection sites were swabbed with sterile saline, and the abdominal wall was closed with suture and wound clips.

Esophagus. The ventral surface of the esophagus was injected with $1-5 \mu \mathrm{l}$ of PRV at a single site equidistant between the gastroesophageal junction and the abdominal surface of the diaphragm. The injection site was swabbed and the incision closed as described above.

Eye. Injections of $4 \mu \mathrm{lPRV}$ were made into the vitreous body of each eye. Direct comparisons of anterograde and retrograde transport rates were made by combining bilateral eye injections with PRV injection into either the tongue $(n=2)$ or stomach $(n=4)$ of the same animal.

Animals recovered from surgery quickly and showed no adverse reaction to PRV prior to $24 \mathrm{hr}$ following injection. Thereafter, animals displayed clinical signs of viral infection consistent with those previously documented for herpes-induced encephalitis (Dolivo et al., 1978; McFarland, 1989; Wittmann and Rziha, 1989). All but 4 of the animals were anesthetized and killed within $54 \mathrm{hr}$ of injection. These animals exhibited only moderate clinical manifestations of viral infection and continued to eat and drink as usual. The remaining 4 animals were allowed to survive for $57,65,69$, and $74 \mathrm{hr}$. These animals exhibited more pronounced clinical signs of infection and were carefully monitored throughout the course of the experiment. Animals in this latter group were anesthetized and killed if they became seriously ill.

\section{CT-HRP injections}

Patterns of neuronal labeling observed following PRV injections were compared to neuronal circuits defined by injection of CT-HRP conjugate. This neuronal tracer is transported in both anterograde and retrograde directions but does not pass transneuronally in detectable levels within the time frame examined in each of these neuronal systems (Trojanowski and Schmidt, 1984; Shapiro and Miselis, 1985a, b; Levine et al., 1986; Johnson et al., 1988; Altschuler et al., 1989; Rinaman et al., 1989a). Additionally, the membrane binding properties of CT-HRP reduce diffusion of the tracer from the injection site (Rinaman and Miselis, 1987), a feature which permits a strict evaluation of PRV dif- 
Table 1. Experimental animals and treatments

\begin{tabular}{lclll} 
Injection site & $\begin{array}{l}\text { Num- } \\
\text { ber of } \\
\text { animals }\end{array}$ & $\begin{array}{l}\text { Virus } \\
(\mu \mathrm{l})\end{array}$ & $\begin{array}{l}\text { Survival } \\
\text { time } \\
(\mathrm{hr})\end{array}$ & $\begin{array}{l}\text { Experimental } \\
\text { treatment }\end{array}$ \\
\hline Tongue & 3 & $1-10$ & $48-50$ & \\
Stomach & 12 & $1-8$ & $24-74$ & \\
Stomach & 2 & 1 & 48 & Cut left nerve \\
Stomach & 2 & 1 & 48 & Cut right nerve \\
Esophagus & 5 & $1-8$ & $24-52$ & \\
Eye & 2 & 4 & $21-24$ & \\
Eye + stomach & 6 & $4(\mathrm{e})$ & $51-57$ & \\
Eye + tongue & 4 & $8(\mathrm{~s})$ & & \\
& & $8(\mathrm{e})$ & $24-48$ & \\
\end{tabular}

"All peripheral injections were made into the musculature of the designated organ with a Hamilton microliter syringe. Stomach injections were relegated to the ventral wall; esophageal injections were confined to the subdiaphragmatic segment. Eye injections were made into the vitreous body. In 6 animals, stomach (s) or tongue $(t)$ injections were combined with bilateral eye $(e)$ injections.

fusion in the same experimental paradigms. In the present analysis, the sites and mode of CT-HRP injections duplicated those used with PRV. The ventral stomach musculature received ten $1 \mu l$ injections of CTHRP, and $10 \mu \mathrm{l}$ of conjugate was injected into the subdiaphragmatic portion of the esophagus. The genioglossis muscle of the tongue was injected with $5 \mu \mathrm{l}$ of conjugatc, and $4 \mu \mathrm{l}$ of CT-HRP was injected into the vitreous body of the eye. Eye- and tongue-injected animals were killed $48 \mathrm{hr}$ postinjection; animals in all other injection paradigms were killed after $72 \mathrm{hr}$. Animal deaths and processing of tissue were carried out according to procedures detailed below.

\section{Histochemical localizations}

\section{Immunohistochemical localization of $P R V$}

Following the indicated postinjection survival period (Table 1), each animal was anesthetized and killed by transcardiac perfusion fixation with paraformaldehyde-lysine-periodate fixative (McLean and Nakane, 1974 ) or $4 \%$ paraformaldehyde in $0.1 \mathrm{~m}$ sodium phosphate buffer at $\mathrm{pH}$ 7.4. The brain was then removed, postfixed in the same fixative, and cryoprotected with phosphate-buffered sucrose as previously described (Card et al., 1981). Serial coronal sections through the caudal brain stem and/or forebrain were cut at $30-40 \mu \mathrm{m}$ with a freezing microtome, and alternate sections were incubated in either the rabbit (Rb134) or goat (g282) antisera. Rb134 was diluted to a final concentration of $1: 500$ to $1: 2000$ with 0.1 M sodium phosphate buffer $\left(\mathrm{NaPO}_{4}\right)$ containing $1 \%$ normal goat serum and $0.3 \%$ Triton $X-100$. The g282 antiserum was diluted to $1: 500-1: 1000$ with $1 \%$ normal rabbit serum and $0.3 \%$ Triton $\mathrm{X}-100$ in the same buffer. In several instances, the tissue was pretreated with sodium borohydride ( $1 \%$ solution in $\mathrm{NaPO}_{4}$ for $10 \mathrm{~min}$ ) followed by methanol/hydrogen peroxide $\left(30 \%\right.$ methanol, $0.5 \% \mathrm{H}_{2} \mathrm{O}_{2}$ in aqueous solution for $5 \mathrm{~min}$ ) prior to antibody incubation to reduce aldehyde cross-linking and endogenous peroxidase activity. These treatments were preceded and followed by extensive buffer washes. After a $24-48 \mathrm{hr}$ antibody incubation at $4^{\circ} \mathrm{C}$, the tissue was processed with the avidinbiotin modification (Hsu et al., 1981) of the immunoperoxidase procedure (Sternberger, 1979) using Vectastain reagents (Vector Laboratorics). The reaction was monitored by periodic microscopic examination of selected tissue sections and was terminated (generally after $10-15 \mathrm{~min}$ ) by several $\mathrm{NaPO}_{4}$ washes. Tissue sections were then mounted on gelatin-coated slides, dehydrated in a graded ethanol series, cleared in xylene, and coverslipped with Permount.

In 2 cases ( 45 and $50 \mathrm{hr}$ survival), the left nodose ganglion and vagus nerve were processed for fluorescence immunohistochemical localization of virus. These experiments utilized the Rb134 antiserum and fluorescein isothiocyanate (FITC)-conjugated antirabbit IgG. Cryoprotected tissue was sectioned at $35 \mu \mathrm{m}$ with a freezing microtome, incubated in a 1:200 dilution of antiserum for $24-48 \mathrm{hr}$ at $4^{\circ} \mathrm{C}$, washed in 3 changes (10 min each) of $\mathrm{NaPO}_{4}$ prior to and following a $30 \mathrm{~min}$ incubation in a 1:50 dilution of FITC. The sections were then mounted on gelatin- coated slides, air-dried, coverslipped with Harleco Krystalon embedding media, and stored at $4^{\circ} \mathrm{C}$ prior to microscopic analysis.

\section{Enzymatic localization of CT-HRP}

Animals injected with CT-HRP were anesthetized with sodium pentobarbitol and killed by sequential transcardiac infusion of $75 \mathrm{ml}$ heparinized salinc (400 units heparin $/ 100 \mathrm{ml}$ salinc), $200 \mathrm{ml}$ dilute fixative $\left(0.1 \%\right.$ paraformaldehyde, $0.5 \%$ glutaraldehyde in $\left.\mathrm{NaPO}_{4}\right), 300 \mathrm{ml}$ concentrated fixative ( 5 times the aldehyde concentration of the dilute fixative), and $250 \mathrm{ml} 10 \%$ phosphate-buffered sucrose. Following overnight storage at $4^{\circ} \mathrm{C}$ in a $20 \%$ sucrose solution, the caudal brain stem or forebrain was sectioned in the coronal plane with a freezing microtome (30-40 $\mu \mathrm{m} / \mathrm{section})$ and processed according to Mesulam's (1982) tetramethylbenzidine (TMB) procedure to localize centrally transported CT-HRP (Shapiro and Miselis, 1985a, b; Rinaman and Miselis, 1987 Rinaman et al., 1989a). After the TMB reaction, sections were rinsed for $5 \mathrm{~min}$ in several changes of ice-cold sodium acetate buffer $(\mathrm{pH} \mathrm{3.3)}$ and quickly mounted on gelatin-coated slides. Slides were dried overnight at $4^{\circ} \mathrm{C}$, rapidly dehydrated in a sodium acetate-buffered ethanol series, and coverslipped with Permount.

\section{Data analysis}

The distribution of PRV-containing neurons was examined at $120 \mu \mathrm{m}$ intervals through the rostrocaudal extent of the diencephalon following eye injections, and in the caudal half of the brain stem following injections of the tongue or gastrointestinal tract. The forcbrain analysis focused upon documented retinal recipient areas of hypothalamus (suprachiasmatic nuclei) and thalamus (geniculate bodies). However, the recent demonstrations of more extensive retinohypothalamic projections (Mai, 1979; Pickard and Silverman, 1981; Riley et al., 1981; Levine et al., 1986; Johnson et al., 1988) necessitated a thorough analysis of the entire hypothalamus. Brain-stem analysis of PRV localization always included the entire rostrocaudal extent of the dorsal motor vagal nucleus/nucleus of the solitary tract (DMV/NST) complex, and in some instances extended as far rostral as the locus coeruleus. Each tissue section was examined at a primary magnification of $200 \times$, and labeled cells were photographed and their locations were mapped upon schematic diagrams.

A detailed quantitative analysis of PRV labeled neurons was conducted on tissue from 4 animals which received injections of PRV into the ventral stomach muculature and the vitreous body of both eyes. Tissue from these animals was sectioned serially through the rostrocaudal extent of the diencephalon and caudal brain stem. Every fourth section was collected for cresyl violet staining. The remaining sections were processed for immunohistochemical localization of PRV with the $\mathrm{Rb} 134$ antiserum, and the number and location of labeled neurons in each section were recorded. Immunoreactive neurons in the diencephalon were grouped according to their localization in either the hypothalamus or lateral geniculate body. Labeled neurons in the caudal brain stem were separated into 3 groups on the basis of their relationship to the area postrema (AP; rostral to the AP, at the level of the AP, and caudal to the AP). The number of PRV-labeled neurons in the DMV and NST at each of these rostrocaudal levels was recorded at 48,51 , 54 , and $57 \mathrm{hr}$ postinjection.

\section{Results}

Each of the experimental paradigms resulted in uptake and transport of PRV to circumscribed populations of neurons in either the brain stem (tongue, stomach, or esophagus injections) or forebrain (eye injections). Both antisera identified the same populations of neurons in adjacent tissue sections. However, the staining intensity achieved with $\mathrm{Rb} 134$ was more robust than that resulting from use of the anti-gIII ( $\mathrm{g} 282$ ) antiserum. Consequently, we have illustrated our results from material prepared with the rabbit polyclonal antiserum.

\section{Patterns of brain-stem labeling and time course of viral transport}

In every case, immunohistochemical localization of virus revealed consistent patterns of cellular labeling which were en- 

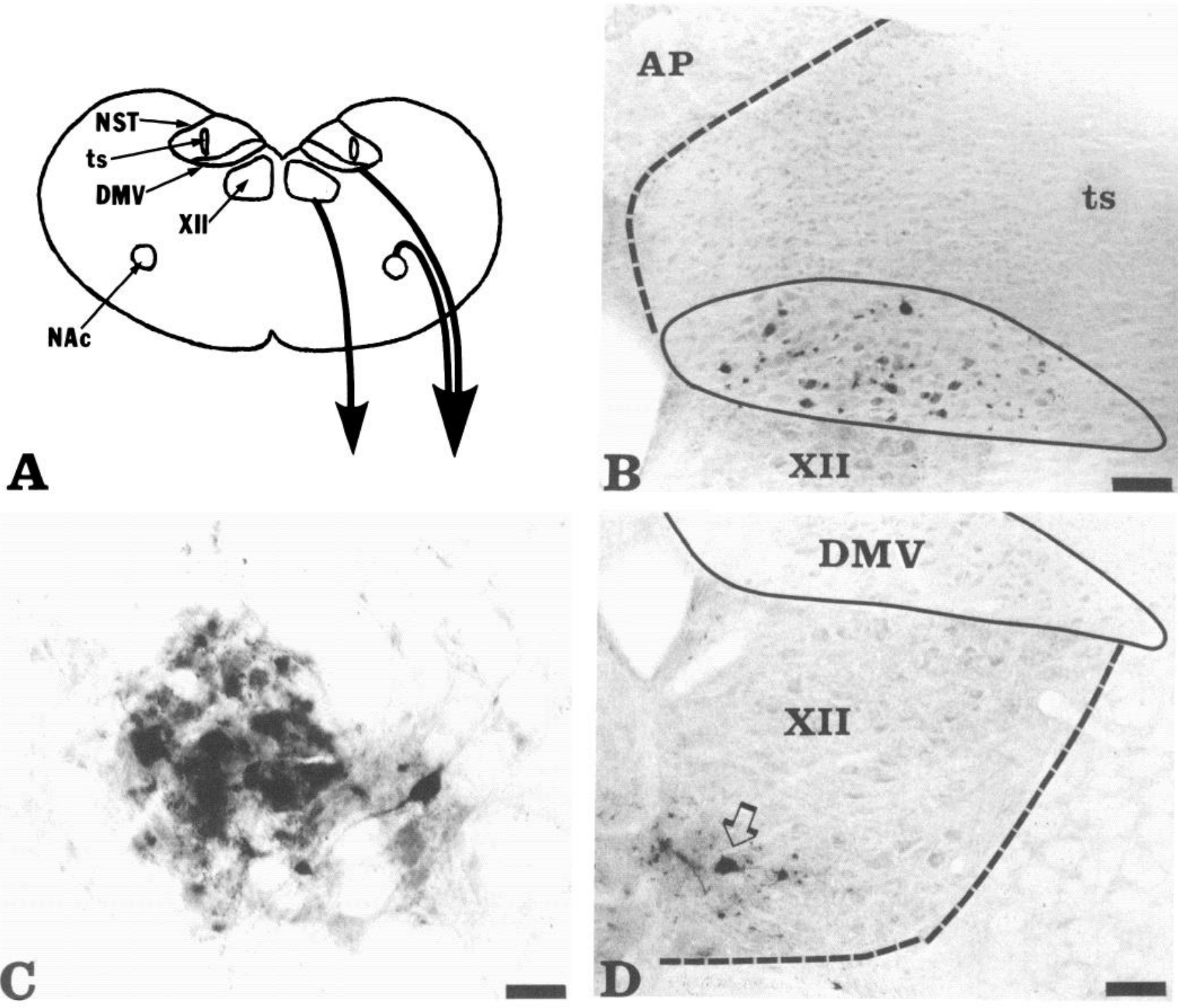

Figure 1. The location of PRV-immunoreactive motor neurons in the rat brain stem following peripheral injection of the ventral surface of the stomach $(B)$, esophagus $(C)$, and tongue $(D)$. The schematic diagram in $A$ illustrates the position of each of these motor cell groups in the caudal brain stem and the course of their efferent axons. Injections of the stomach resulted in retrograde transport of virions to neurons in the dorsal motor nucleus of the vagus $(D M V)$. By contrast, injections of the esophagus and tongue led to PRV labeling of neurons in the nucleus ambiguus and hypoglossal nucleus, respectively. NST, nucleus of the solitary tact; $t s$, tractus solitarius; $X I I$, hypoglossal nucleus; NAc, compact portion of the nucleus ambiguus. Scale bars for $B$ and $D, 235 \mu \mathrm{m}$; for $C, 125 \mu \mathrm{m}$.

tirely dependent upon the site of injection and the postinjection survival time. However, several aspects of the cellular localization of PRV were common to all injection paradigms and provide important insight into the specificity of viral transport through these brain-stem circuits. First, astroglial labeling always followed neuronal labeling in the temporal sequence of infection. Following injections of the tongue, stomach, or esophagus, virus was first observed in brain-stem motor neurons and axons known to innervate these peripheral organs (i.e., hypoglossal, dorsal vagal, and ambiguus motor neurons, respectively; Fig. 1, $A-D$ ). The number and staining intensity of infected motor neurons increased progressively with time, and ultimately PRV infection led to vacuolization and degeneration of the most severely afflicted neurons. Loss of integrity of these neuronal perikarya was accompanied by uptake and replication of virions by astroglia in the immediate vicinity (Figs. $2, A-C ; 3, A-C$ ). The number of infected astroglia increased with time but never spread from the primary site of infection. At approximately 50 $\mathrm{hr}$ postinjection, a second population of $\mathrm{PRV}$-immunoreactive neurons became apparent (Figs. 2, B, $C ; 3, A, B$ ). The distribution of these cells differed in each of the experimental paradigms but was extremely consistent among animals of the same group. Initially, these second-order neurons were not associated with immunoreactive astroglia. However, with increasing postinjection intervals (52-74 hr), PRV-containing astroglia were associated with second-order neurons, and the number of immunoreactive astroglia associated with these cells increased with time. Finally, 2 points should be emphasized. First, with the 

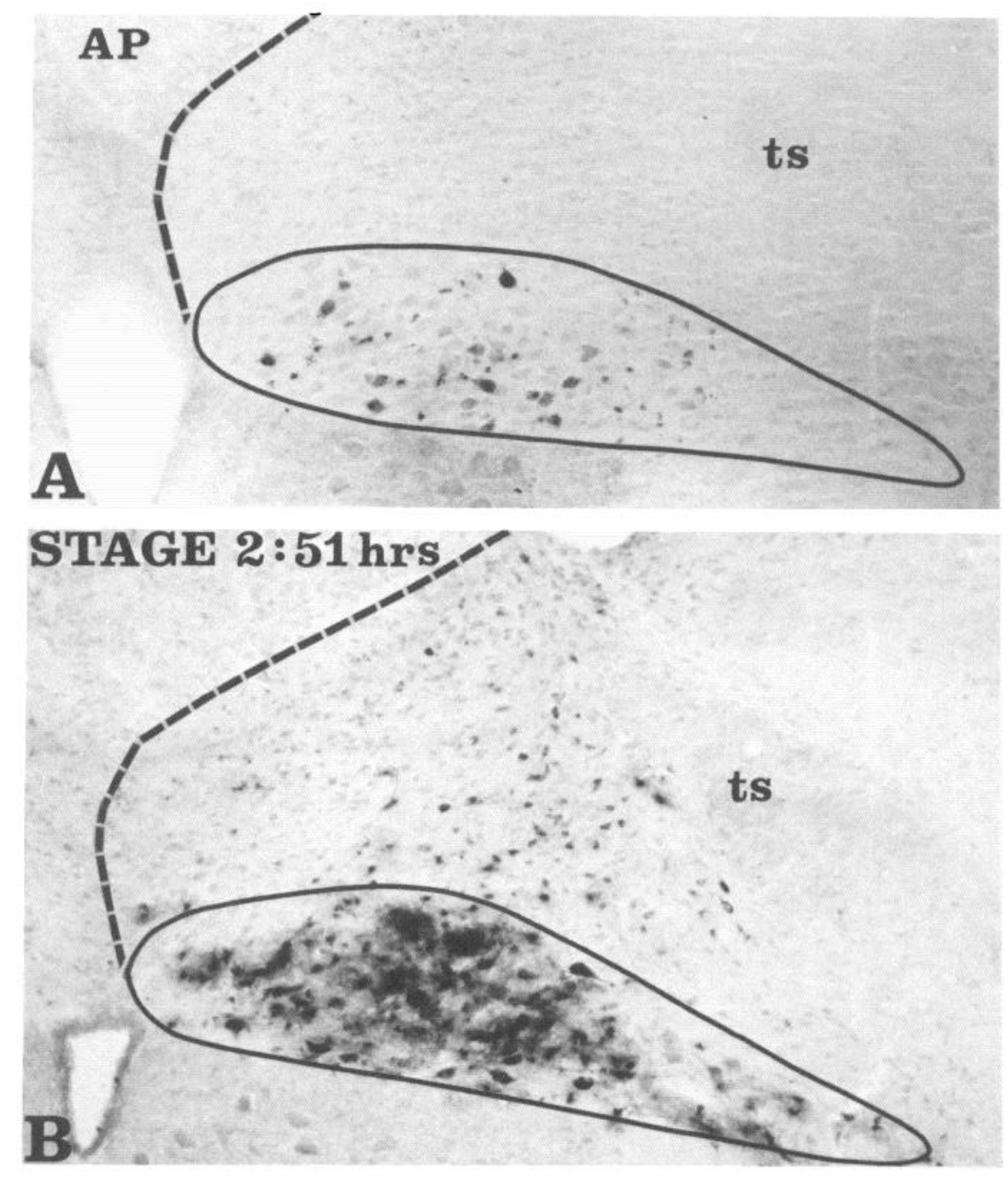

Figure 2. The distribution of immunoreactive neurons in early $(A)$, intermediate $(B)$, and advanced $(C)$ stages of infection following injection of PRV into the ventral stomach musculature. Increasing numbers of immunoreactive motor neurons are present in the DMV (demarcated by the solid line) with advancing survival, and immunoreactive second-order neurons and astroglia observed in intermediate and advanced stages are confined to the medial division of the nucleus of the solitary tract (NST). ts, tractus solitarius. Scale bar, $250 \mu \mathrm{m}$.

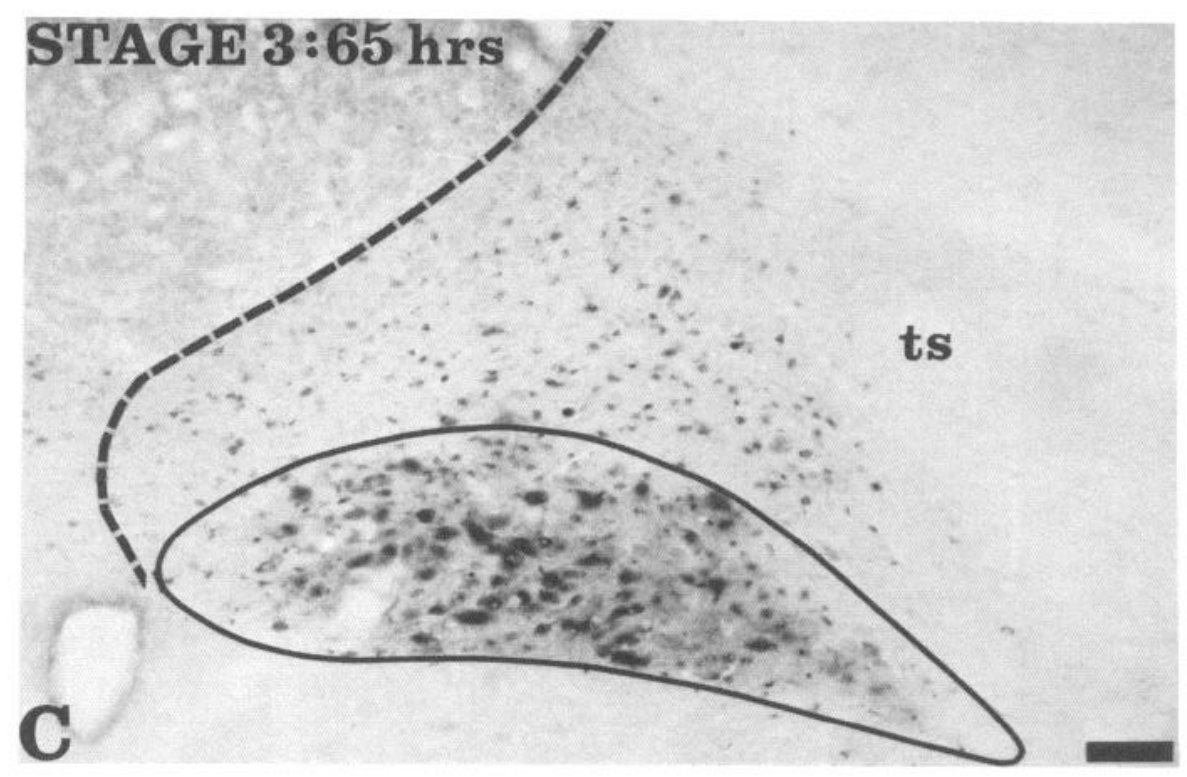



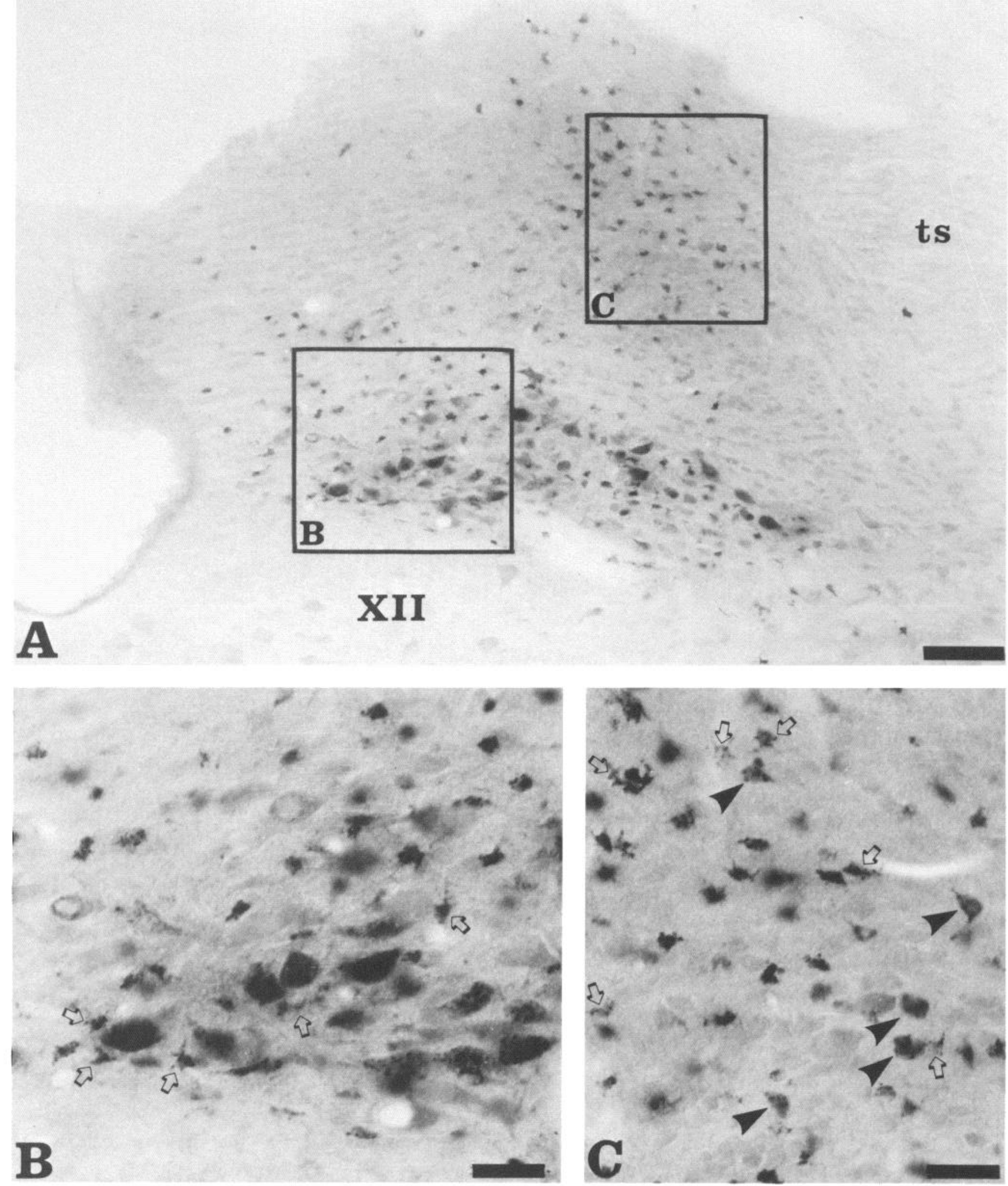

Figure 3. Distribution of PRV immunoreactivity in the DMV/NST complex $74 \mathrm{hr}$ following injection of $1 \mu \mathrm{l}$ PRV into the ventral stomach musculature. The tissue section is slightly rostral to that illustrated in Figure $2 A$. Areas boxed in $A$ are illustrated at higher magnification in $B$ and $C$. Note the discrete cellular labeling apparent in both the DMV and NST and the lack of spread of virus to adjacent brain-stem nuclei. Examination of PRV localization at higher magnification reveals that the virus is present in neurons (examples in NST noted by arrowheads) surrounded by small infected astroglial cells (open block arrows). $X I I$, hypoglossal motor nucleus; $t$, tractus solitarius. Scale bar for $A, 100 \mu \mathrm{m}$; for $B$ and $C$, 25 $\mu \mathrm{m}$. 

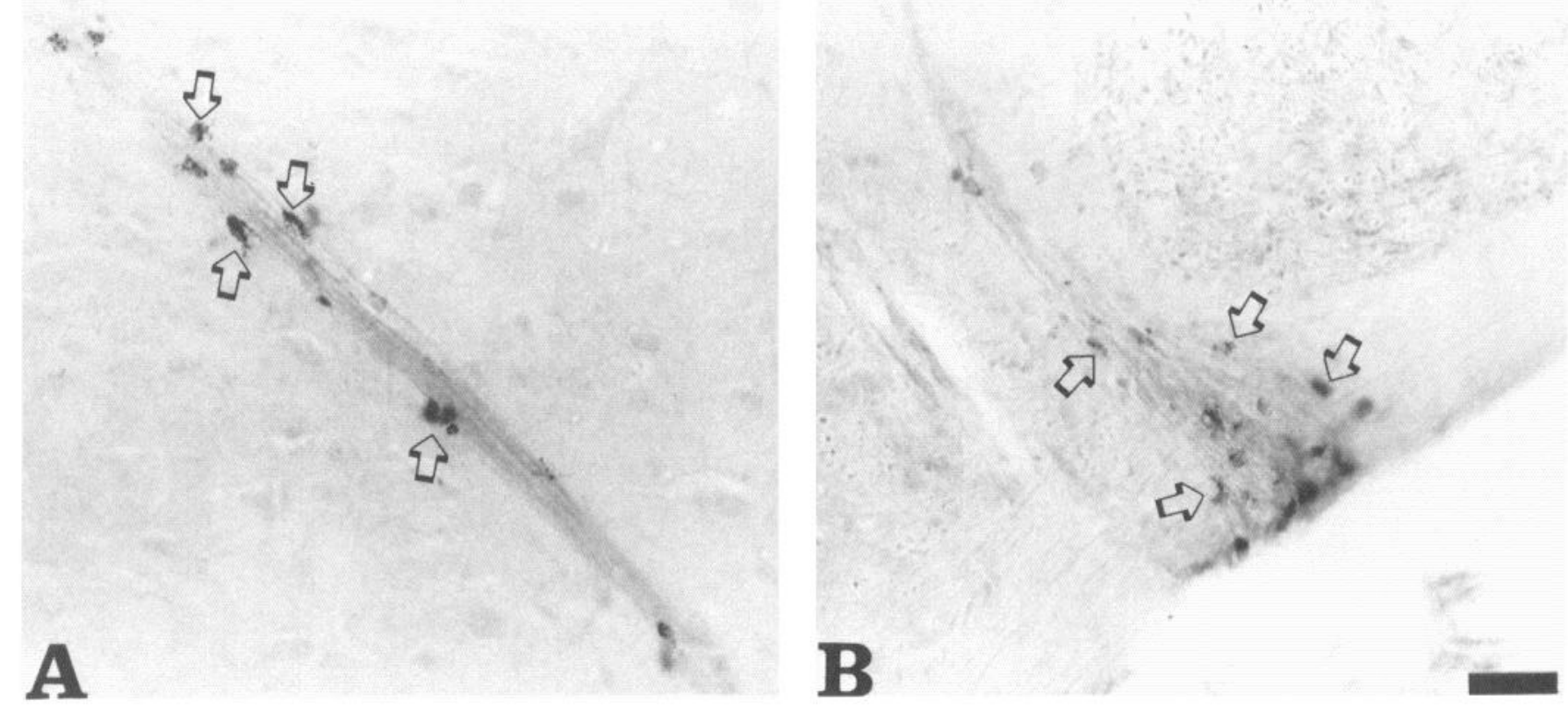

Figure 4. $A$ and $B$, Distribution of PRV immunoreactivity in motor axons of the vagus nerve following injection of the stomach musculature. Immunoreactive glia (arrows) were associated with infected axons throughout their course through the brain stem $(A)$ and were particularly evident around motor rootlets at the junction of the nerve and brain. Scale bar, $125 \mu \mathrm{m}$ for both figures.

exception of the efferent motor axon tract, glial labeling was confined to the vicinity of first- and second-order neurons. Second, there was no neuronal labeling along the course of infected efferent axons, even in cases in which these axons were associated with PRV-immunoreactive astroglia (Fig. 4, $A, B$ ).

\section{Tongue injections}

Transport of HSV-1 virions through brain-stem circuits influencing motor function of the tongue was previously reported by Ugolini and collaborators (1987). We included this experimental paradigm in our analysis to evaluate the neurotropic properties of PRV under established conditions. In addition, the direct proximity of the hypoglossal nucleus to the DMV/NST complex (the latter being the primary focus of the present study) provided an excellent means of evaluating nonspecific spread of virus from PRV-infected motor neurons. Our analysis of this projection system (7 animals; $30-52 \mathrm{hr}$ survival) corroborated the findings of Ugolini et al. (1987) in all respects (Fig. 5, $A-F$ ). Following injection of the ventrolateral tongue musculature, light PRV immunoreactivity was first evident in scattered hypoglossal motor neurons $30 \mathrm{hr}$ postinjection. The number of infected neurons and the intensity of immunoreactivity within individual cells increased progressively with longer survival times but showed no evidence of nonspecific spread from the hypoglossal motor nucleus. Individual neurons exhibited prominent accumulations of immunoperoxidase within both the cell nucleus and cytoplasm (Fig. 5A), and immunoreactive astroglia were present adjacent to the most severely afflicted perikarya. By 48-52 hr postinjection, PRV immunoreactivity was apparent in a circumscribed population of second-order neurons (Fig. 5, $A, C-F)$. The largest number of PRV-containing second-order neurons were confined to pars oralis and pars interpolaris of the spinal trigeminal nucleus (Fig. $5 C$ ), and the brain-stem tegmentum lateral and ventral to the hypoglossal nucleus (Fig. $5 D$ ).
At the longest postinjection time interval examined in this injection paradigm $(52 \mathrm{hr}), \mathrm{PRV}$ immunoreactivity was also present in neurons of the raphe nuclei (nucleus obscurus and nucleus pallidus) and in neurons of the ventrolateral brain-stem tegmentum which were similar in morphology and distribution to monoaminergic cell groups in this area (Fig. $5 E$ ).

Several aspects of the brain-stem labeling observed following tongue injections demonstrated specificity of both uptake and transport of PRV. The distribution of labeled motor neurons was entirely dependent upon the site of injection; unilateral injections resulted in PRV immunoreactivity confined to motor neurons in the ipsilateral nucleus, whereas injection of both sides of the tongue labeled hypoglossal neurons bilaterally (data not shown). Similarly, evidence that there was very little diffusion of PRV from the site of injection was apparent in comparing the viral brain-stem labeling resulting from injection of individual tongue muscles with CT-HRP conjugate (Fig. 5, $A, B$ ). In both instances, injection of the ventral tongue musculature resulted in labeling of neurons located principally in the ventral half of the hypoglossal nucleus. Finally, the distribution of PRV in both first- and second-order neurons was very consistent in all experimental animals. In every instance, PRV immunoreactivity was confined to hypoglossal motor neurons and secondorder neurons in the spinal trigeminal nucleus, brain-stem tegmentum, and monoaminergic cell groups.

\section{Stomach injections}

Immunohistochemical analysis of brain-stem circuits labeled by PRV injection (1-10 $\mu$ l) into the ventral stomach musculature was conducted $21-74 \mathrm{hr}$ following virus injection. This injection paradigm resulted in viral localization in motor neurons of the DMV, and the pattern of motor neuron labeling was equivalent to that observed after injection of CT-HRP (Fig. 6, $A-H$ ). The first evidence of PRV localization in the brain stem occurred at 

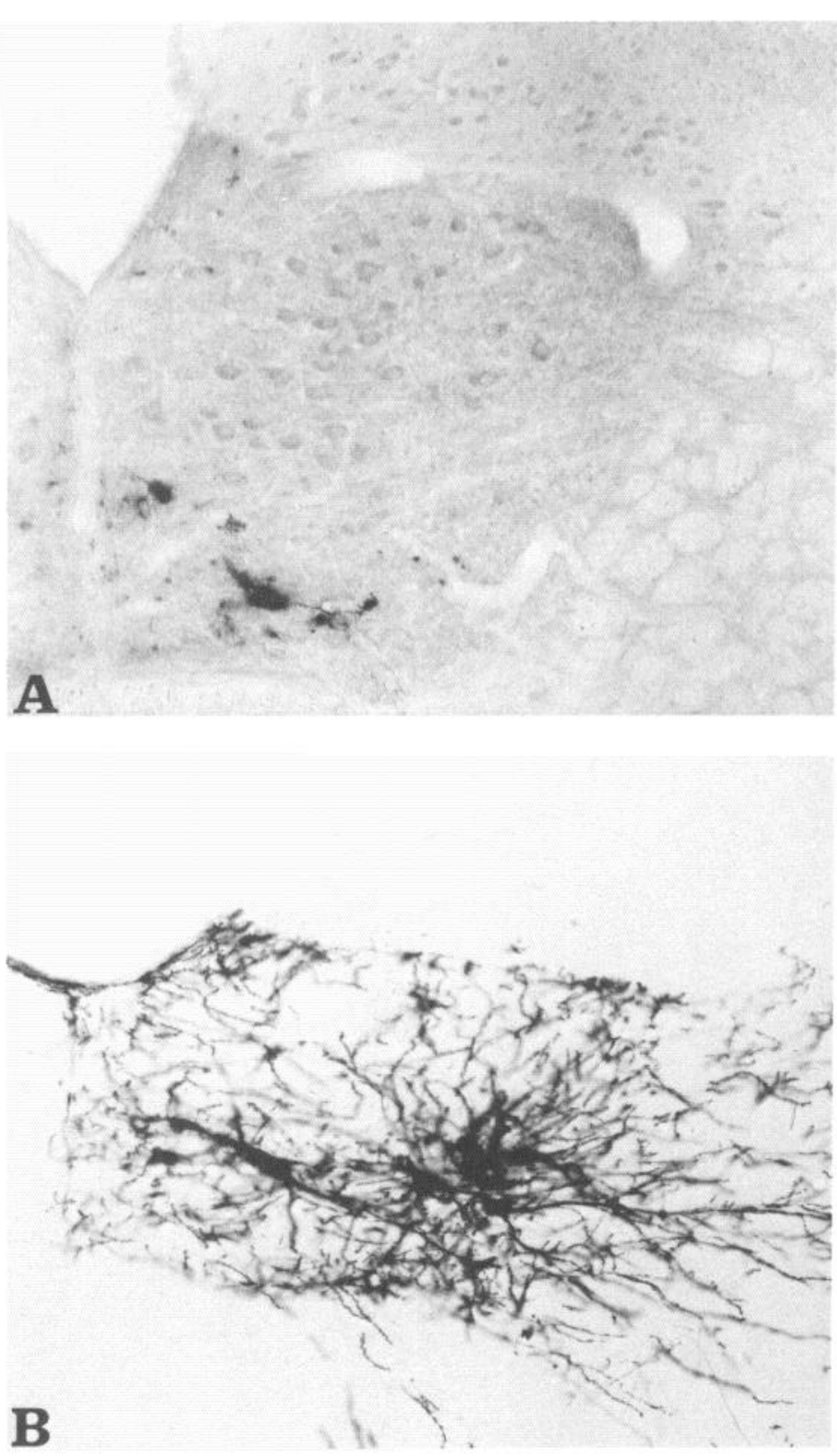
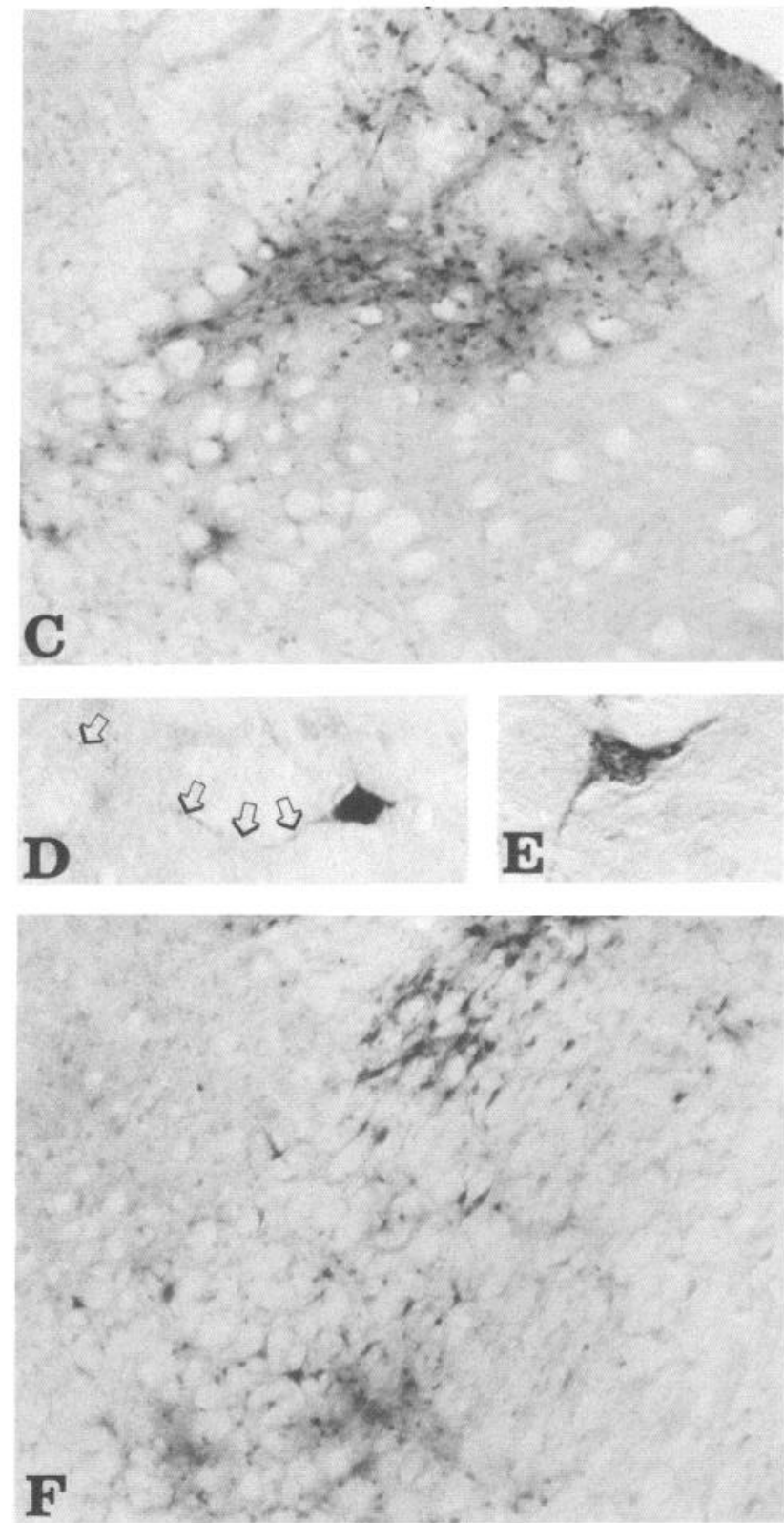

Figure 5. Distribution of PRV immunoreactivity in first- and second-order neurons of the rat brain following injection of the ventrolateral tongue musculature. First-order neuron labeling was restricted to motor neurons in the hypoglossal nucleus $(A)$ in a pattern analogous to that observed following CT-HRP injection into the genioglossis muscle $(B)$. Second-order neuron labeling was prevalent in the dorsomedial aspect of the spinal trigeminal nucleus $(C)$ and in the ventrolateral brain-stem tegmentum $(F)$. Scattered PRV-containing neurons were also found immediately lateral to the hypoglossal nucleus $(D)$ and in the vicinity of adrenergic cell groups $(E)$. Note the PRV immunoreactivity in the varicose axon of the cell in $D$ (arrows); this axon courses toward the hypoglossal nucleus. Scale bars for $A$ and $B, 250 \mu \mathrm{m}$; for $C$ and $F, 135 \mu \mathrm{m}$; for $D$ and $E, 25 \mu \mathrm{m}$.

$30 \mathrm{hr}$ postinjection when light immunoreactivity was evident in a small number of DMV motor axons and their cells of origin. By $48 \mathrm{hr}$, large numbers of immunoreactive neurons were present in the left DMV, and the pattern of motor neuron labeling was remarkably consistent with that observed following injection of CT-HRP; large numbers of retrogradely labeled neurons were present throughout the rostrocaudal extent of the left DMV but were absent from the lateral pole of the nucleus (Figs. 6, $A-$ $H ; 7 A)$. By contrast, only scattered labeled neurons were apparent in the right DMV (Fig. $7 A$ ). Severance of the left vagus nerve prior to injection of the ventral stomach eliminated immunoreactive neurons in the left DMV but did not affect trans- port of virus to scattered neurons in the right DMV (Fig. $7 B$ ). Similarly, sectioning the right vagus nerve prior to PRV injection eliminated all immunoreactivity in the right DMV but had no obvious effect upon PRV labeling in the left DMV (data not shown). All of these results are consistent with specific uptake and axonal transport of PRV within a known projection system and also indicate that there is very little spread of the virus from the site of injection.

The principal feature which distinguished later stages of infection was the appearance of second-order neurons in the NST (stage 2). This cell population was first evident at $48 \mathrm{hr}$ survival and increased in both cell number and staining intensity through 

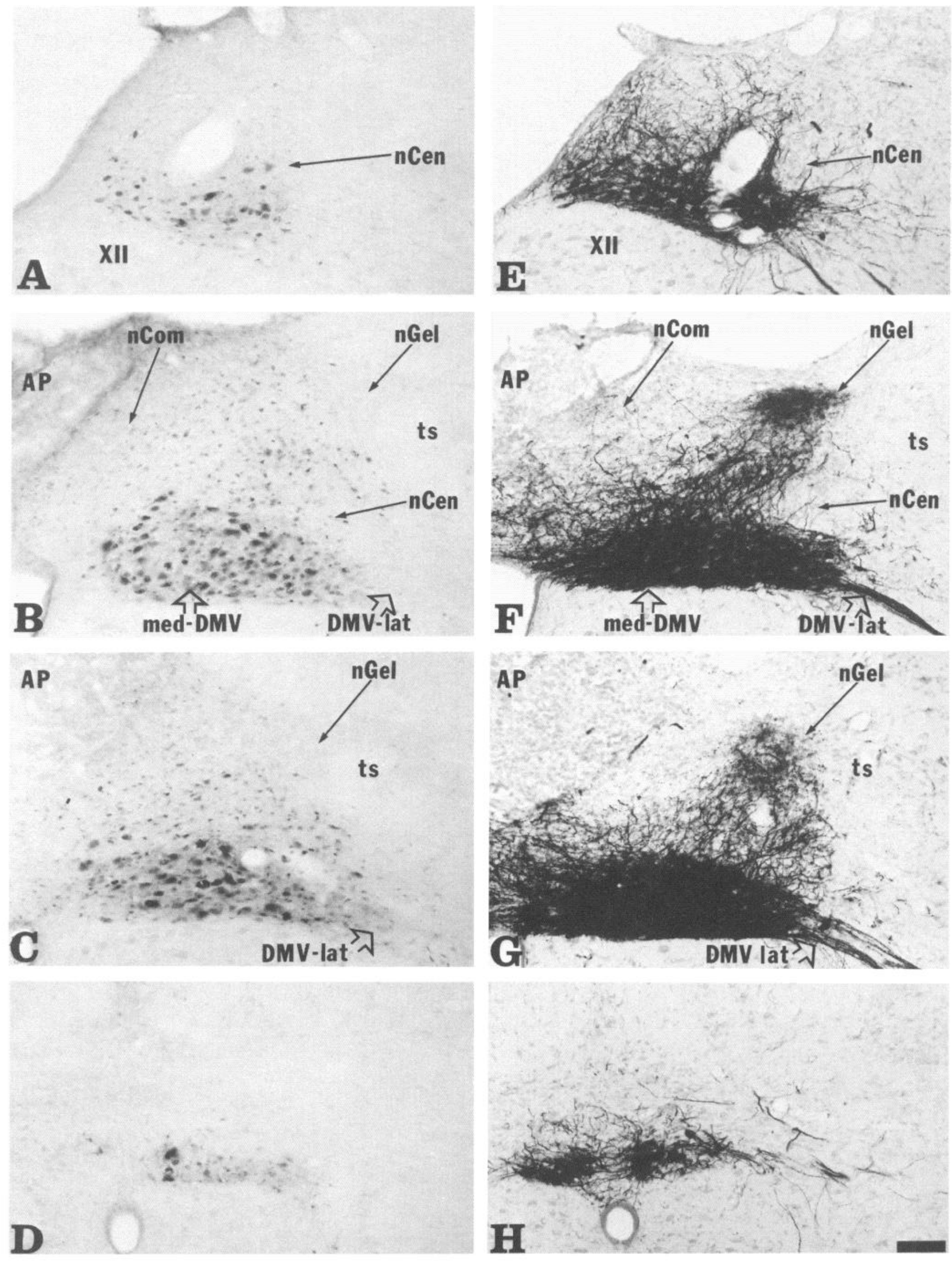


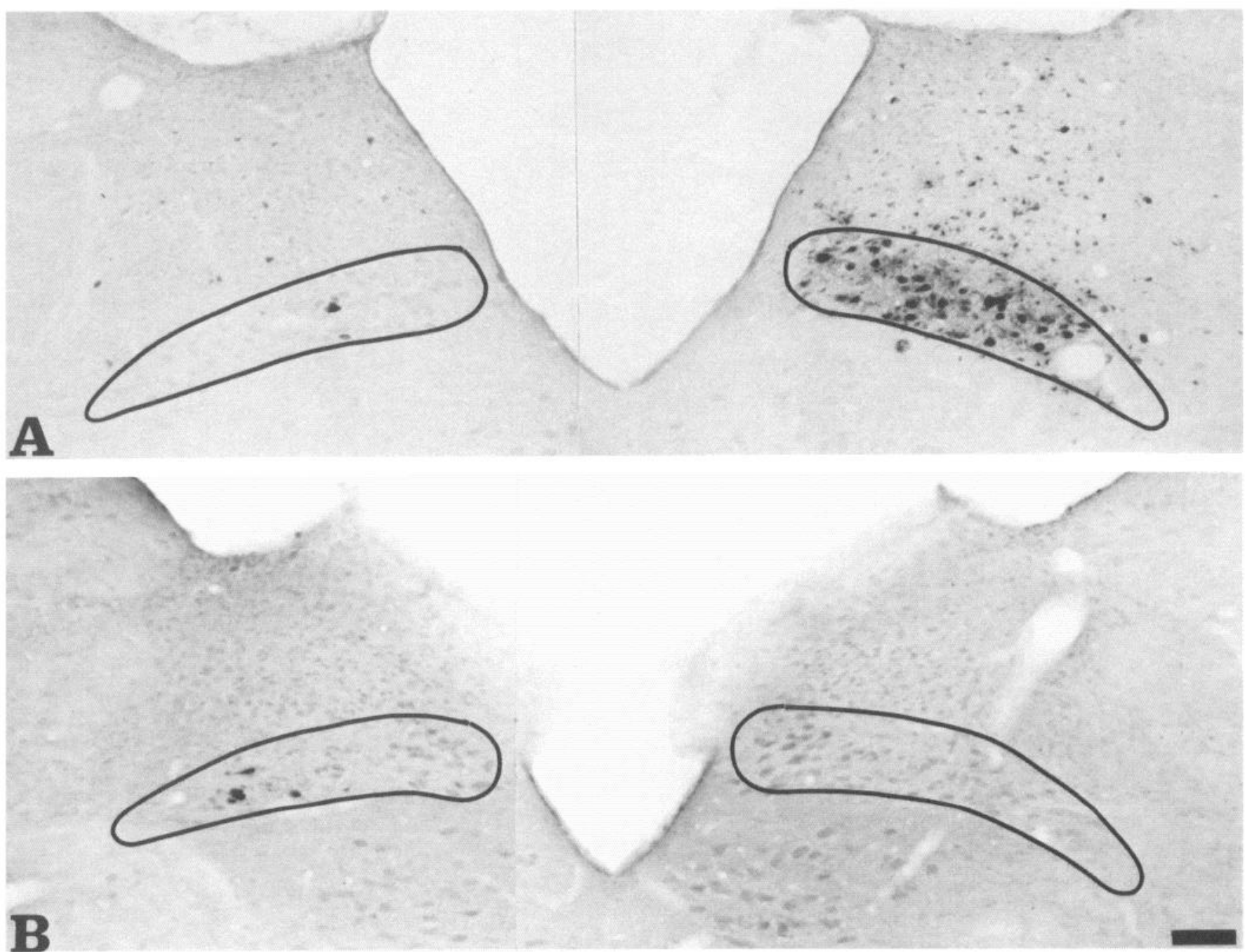

Figure 7. Distribution of PRV-labeled gastric neurons in the brain stem observed under the normal circumstances $(A)$ and following cervical vagotomy $(B)$. At $48 \mathrm{hr}$ after injection of the ventral stomach musculature, large numbers of labeled motor neurons are present in the left DMV, while only scattered immunoreactive motor neurons are present in the right DMV $(A)$. When the PRV injection is preceded by removal of a 5 mm segment of the left vagus nerve, no immunoreactive perikarya are present in the left DMV, but the scattered immunoreactive cells in the right DMV persist $(B)$. Also note the loss of immunoreactive second-order neurons in the vagotomized animal. Scale bar, $365 \mu \mathrm{m}$ for $A$ and $B$.

$74 \mathrm{hr}$. Labeled second-order neurons were differentially concentrated in the medial division of the NST, in an area coextensive with the dendritic field of gastric vagal motor neurons (compare Fig. 6, $A-D$ and $E-H$ ). PRV-immunoreactive secondorder neurons were strictly confined to the medial division of the NST and were most prevalent at the level of the area postrema (AP). At $53 \mathrm{hr}$ following injection, immunoreactive astroglia became apparent in association with infected NST second-order neurons (Fig. 3C). Quantitative analysis of neuronal labeling at $48,51,54$, and $57 \mathrm{hr}$ postinjection clearly demonstrated that the number of PRV-containing neurons in the DMV and medial NST increased progressively with advancing sur- vival time (Figs. 8, 9). In addition, this analysis demonstrated that the majority of second-order neurons in the NST were concentrated in the rostral two-thirds of this cell column, with only scattered immunoreactive perikarya caudal to the AP (Fig. 9).

The distribution of PRV-immunoreactive cells in the DMV/ NST reflected the only brain-stem localization of PRV immunoreactivity at times less than $65 \mathrm{hr}$ after injection. At 69 and $74 \mathrm{hr}$ postinjection, the distribution of PRV immunoreactivity in the DMV/NST was essentially identical to that observed at $64 \mathrm{hr}$. However, a moderate number of PRV-immunoreactive perikarya were also present in the raphe nuclei and the locus

Figure 6. Distribution of gastric circuitry revealed by PRV $(A-D)$ or CT-HRP $(E-H)$ injection into the ventral stomach musculature is compared at 4 representative levels of the DMV/NST complex. PRV-labeled motor neurons are present throughout the rostrocaudal extent of the DMV $(A$ is most rostral; $D$ is furthest caudal) in a pattern that is essentially identical to the distribution of neurons labeled with CT-HRP. PRV-labeled second-order neurons are concentrated in the medial division of the NST at intermediate levels of the DMV $(B$ and $C)$. The terminal arbor of sensory afferents arising in the stomach forms a dense terminal plexus in the subnucleus gelatinosis ( $n G E L)$. nCOM, subnucleus commissuralis; $n C E N$, subnucleus centralis; $t s$, tractus solitarius; med, medial; lat, lateral. Scale bar, $365 \mu \mathrm{m}$ for all figures. 


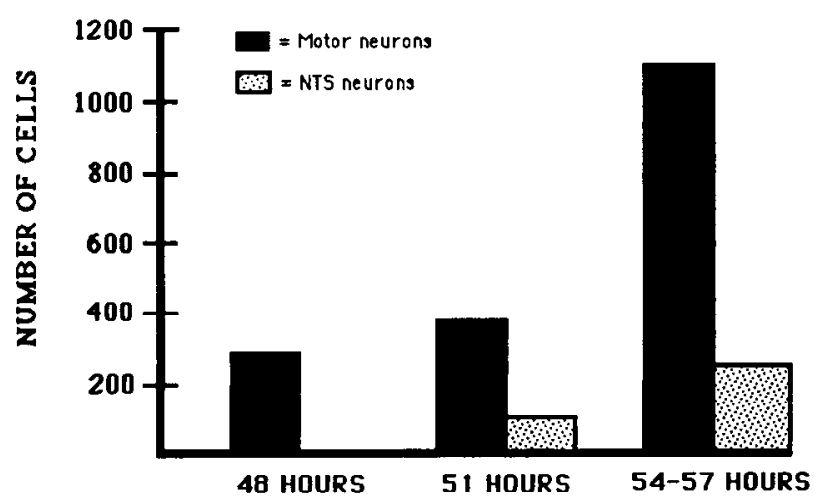

Figure 8. Number of PRV-labeled first- and second-order neurons in the DMV/NST following stomach injection. See the text for details regarding the method of quantitation.

coeruleus at these later time points. The majority of these cells were found in the raphe obscurus and raphe pallidus at levels rostral to the $\mathrm{AP}$ (Fig. 10, $A, B$ ). Only occasional neurons were ohserved in the locus coeruleus (Fig. 10C), and we never observed immunoreactive neurons in a limited survey of the midbrain or forebrain.

Examination of the vagus nerve at the level of the nodose ganglion and in its course through the brain stem revealed PRV immunoreactivity in motor axons at all time points. As indicated previously, immunoreactive axons were evident in the efferent tract of the vagus nerve within $30 \mathrm{hr}$ of injection and the number and staining intensity increased with time. By contrast, although PRV-immunoreactive sensory neurons were present in the nodose ganglion at 45 and $50 \mathrm{hr}$, immunoreactivity was not observed in sensory afferents in the brain stem as long as $64 \mathrm{hr}$ after injection of the stomach. In every case, the tractus solitarius was devoid of immunoreactive fibers and astroglia, even though there were large numbers of immunoreactive second-order neurons in the medial division of the NST, immediately adjacent to the tractus (Figs. 3, $A-C ; 6, A-$ $D ; 7, A, B)$. At the longest postinjection intervals $(69$ and 74 $\mathrm{hr}$ ), a few lightly stained immunoreactive sensory afferents were observed in the tractus.

\section{Esophagus injections}

Injections of the subdiaphragmatic esophagus produced a pattern of labeling in the brain stem distinct from that observed following injections of either the stomach or tongue (Fig. 11, $A-D$ ). PRV injections confined to the esophageal musculature produced prominent labeling in motor neuron somata, dendrites, and efferent axons of the nucleus ambiguus but did not label any other motor neuron pool in the brain stem (Fig. 11, $C, D$ ). The majority of PRV-immunoreactive motor neurons were concentrated in the compact portion (Bieger and Hopkins, 1987) of the rostral third of this cell column, and the cell distribution was essentially identical to that observed following injection of CT-HRP in the same region of the esophagus (data not illustrated).

At times longer than $48 \mathrm{hr}$ postinjection, PRV-labeled secondorder neurons were present in a circumscribed region of the medial NST known as the nucleus centralis (nCen; Fig. $11 D$ ). As with the other injection paradigms, the number and staining intensity of these small, bipolar neurons increased with time, and they were ultimately associated with infected astroglia. The

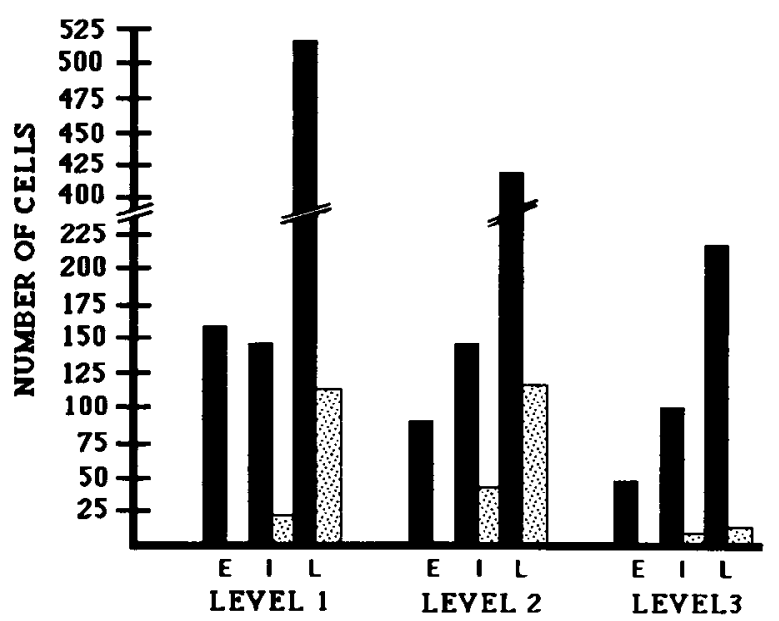

Figure 9. Same data as in Figure 8 displayed differently. Levels 1-3 are designated on the basis of the relationship of the DMV/NST to the area postrema $(A P)$; sections rostral to the AP are grouped as level 1 , level 2 is at the level of the AP, and level 3 is caudal to the AP. Data within each level are also separated on the basis of postinjection survival ( $E$, early; $I$, intermediate; and $L$, late). Note the differential concentration of second-order neurons in portions of the DMV/NST, which are at the level of the AP and just rostral to it.

nCen was also the site of dense terminal arborization of esophageal vagal sensory afferents revealed by CT-HRP injection (Fig. $11 B$ ). However, there was no indication that the PRV immunoreactivity observed in the nCen was the result of anterograde transport of virions through these sensory afferents. By contrast, the tractus was devoid of PRV immunoreactivity in the same animals which exhibited dense staining of second-order neurons in the nCen (Fig. 11D).

\section{Anterograde viral transport through visual circuits}

Injcction of the vitreous body of the eye resulted in PRV uptake by retinal ganglion cells and anterograde transport of virions to retinal recipient areas of the forebrain. At the earliest time point examined ( $21 \mathrm{hr}$ postinjection), PRV-immunoreactive ganglion cells were present at the peripheral aspects of the retina. By 24 $\mathrm{hr}$, the number of immunoreactive ganglion cells had increased and PRV immunoreactivity was prominent in optic axons on the vitreal surface of the retina. These immunoreactive fibers converged upon the optic papilla and extended in to the proximal segment of the optic nerve (Fig. 12, $A, C$ ). However, immunoreactive axons were not observed in the optic chiasm or tracts at this stage of transport, and there was very little evidence of transneuronal passage of the virus into deeper layers of the retina. By $48 \mathrm{hr}$, immunoreactive ganglion cells were apparent across the full extent of the retina and the intensity of immunoreactivity in optic fibers had increased dramatically. In addition, PRV immunoreactivity was evident in columns of cells which extended into the deeper layers of the retina. The cells forming these columnar arrays were in contact with one another, and the column often traversed the full extent of the retina. At subsequent stages postinjection, the number of immunoreactive ganglion cells increased and PRV invasion of the retina was so advanced that focal areas of cellular necrosis extended through all retinal layers. In addition, immunoreactivity in optic axons on the vitreal surface of the retina increased dramatically and often was associated with necrosis at the papilla (Fig. 12B).

The first evidence of PRV immunoreactivity in the dien- 

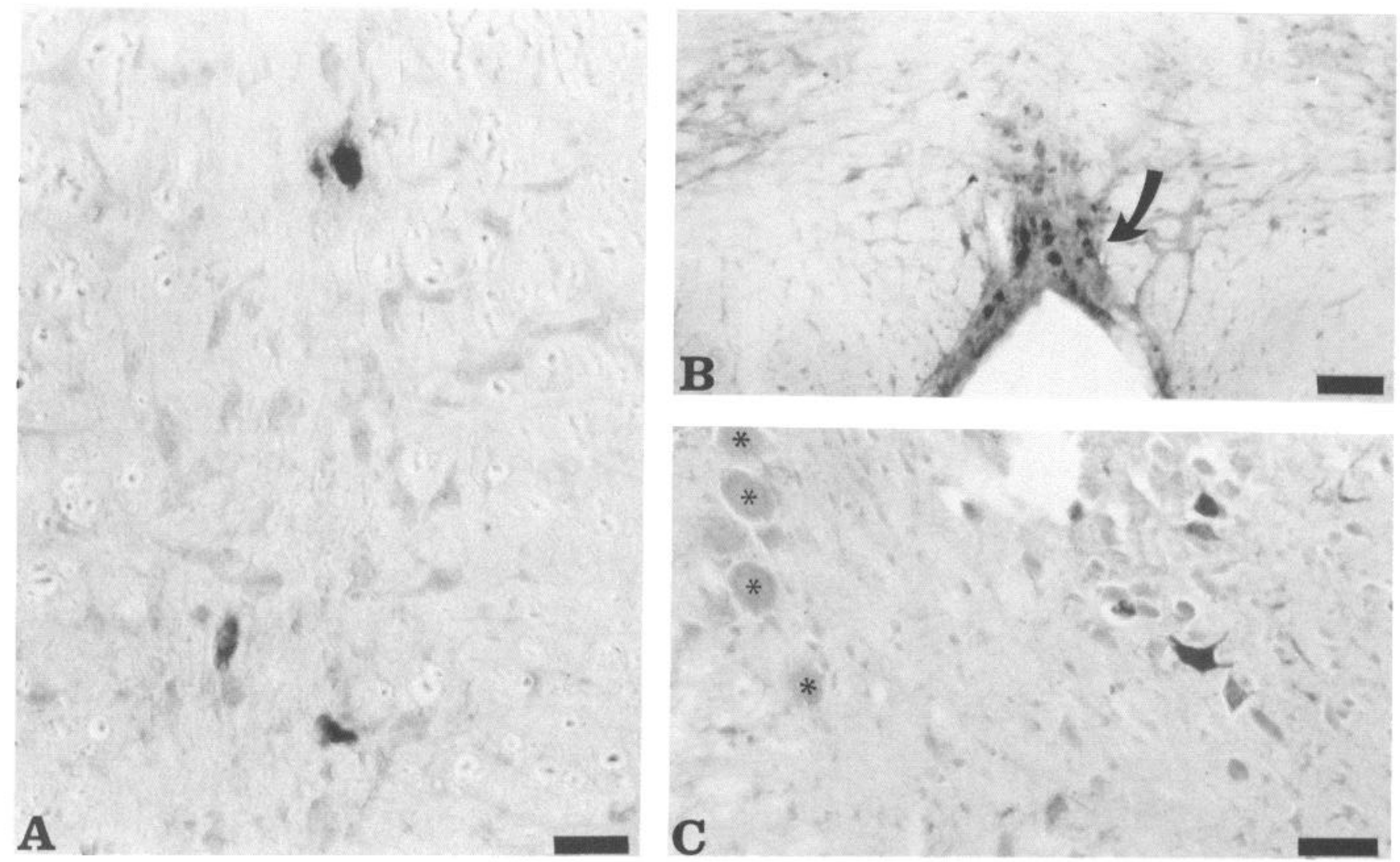

Figure 10. PRV-immunoreactive neurons in the raphe obscurus $(A)$, the raphe pallidus (arrow in $B)$, and the locus coeruleus $(C)$. These neurons are from a stomach injected case of $69 \mathrm{hr}$ survival. Asterisks $\left(^{*}\right)$ designate neurons of the mesencephalic nucleus of $\mathrm{V}$. Scale bar for $A, 25 \mu \mathrm{m}$; for $B, 12 \mu \mathrm{m}$; for $C, 10 \mu \mathrm{m}$.

cephalon occurred at $51 \mathrm{hr}$ postinjection. Immunohistochemical localization of PRV in neurons at this and subsequent times demonstrated a clear transneuronal passage of virus into nuclear groups which are known to receive dense synaptic input from retinal terminals (phase 2; Fig. 13, $A-F$ ). The hypothalamus contained small numbers of PRV-immunoreactive neurons in the suprachiasmatic nuclei (SCN; Fig. 13A), the retrochiasmatic area, the anterior and lateral hypothalamic areas (Fig. 13B), and in 2 of the 3 subdivisions of the lateral geniculate body (Fig. $13, C-F)$. Immunoreactive neurons in the SCN were confined to the ventrolateral subdivision of the nucleus which is known to receive dense retinal input. Immunoreactivity in the lateral geniculate body was concentrated in the ventral aspect of the dorsal lateral geniculate nucleus (dLGN) and in scattered neurons in the ventral lateral geniculate nucleus (vLGN). By contrast, the intergeniculate leaflet (IGL) never exhibited immunoreactive perikarya within the time frame of this analysis (48$57 \mathrm{hr}$ ). PRV immunoreactivity in the dLGN and vLGN was observed in both afferent axons and neuronal perikarya. Immunolabeling of retinal afferents revealed a characteristic pericellular arborization of varicose fibers. These varicose, pericellular arbors often ensconced the perikarya and proximal dendrites of cells which themselves exhibited no detectable PRV immunoreactivity (Fig. 13, D, E). In other instances, immunoreactive terminal arbors surrounded the perikarya and dendrites of PRV-immunoreactive cells (Fig. 13F).

\section{Anterograde versus retrograde transport}

PRV transport from the retina was used as an index to compare rates of anterograde versus retrograde transport in 4 animals which received PRV injections in both eyes and the ventral stomach musculature. These animals were selected for quantitation because all 3 stages of PRV transport and replication are represented, and the principal second-order neuron population in the brain stem consists of a circumscribed population of cells confined to the immediately adjacent NST. The forebrain and brain stem of these animals were sectioned serially, and the number of neurons exhibiting PRV immunoreactivity in the DMV/NST at $48,51,54$ and $57 \mathrm{hr}$ were recorded using the method described previously. This comparison demonstrated that retrograde transport of the virus from the stomach occurred at a much faster rate than anterograde transport from the eye, even though the retinal axons are much shorter than the vagal axons. At $48 \mathrm{hr}$ postinjection, approximately 300 motor neurons in the left DMV exhibited PRV immunoreactivity in response to injection of the stomach, but there was no evidence of PRV immunoreactivity in the optic chiasm or tracts. Furthermore, no transneuronally labeled neurons were present in retinal recipient areas of the forebrain at this survival time (Figs. 8, 9, 14). With advancing time, the number of PRV-labeled firstorder neurons increased progressively (approximately 1200 in the left DMV) and transneuronal labeling of second-order neu- 

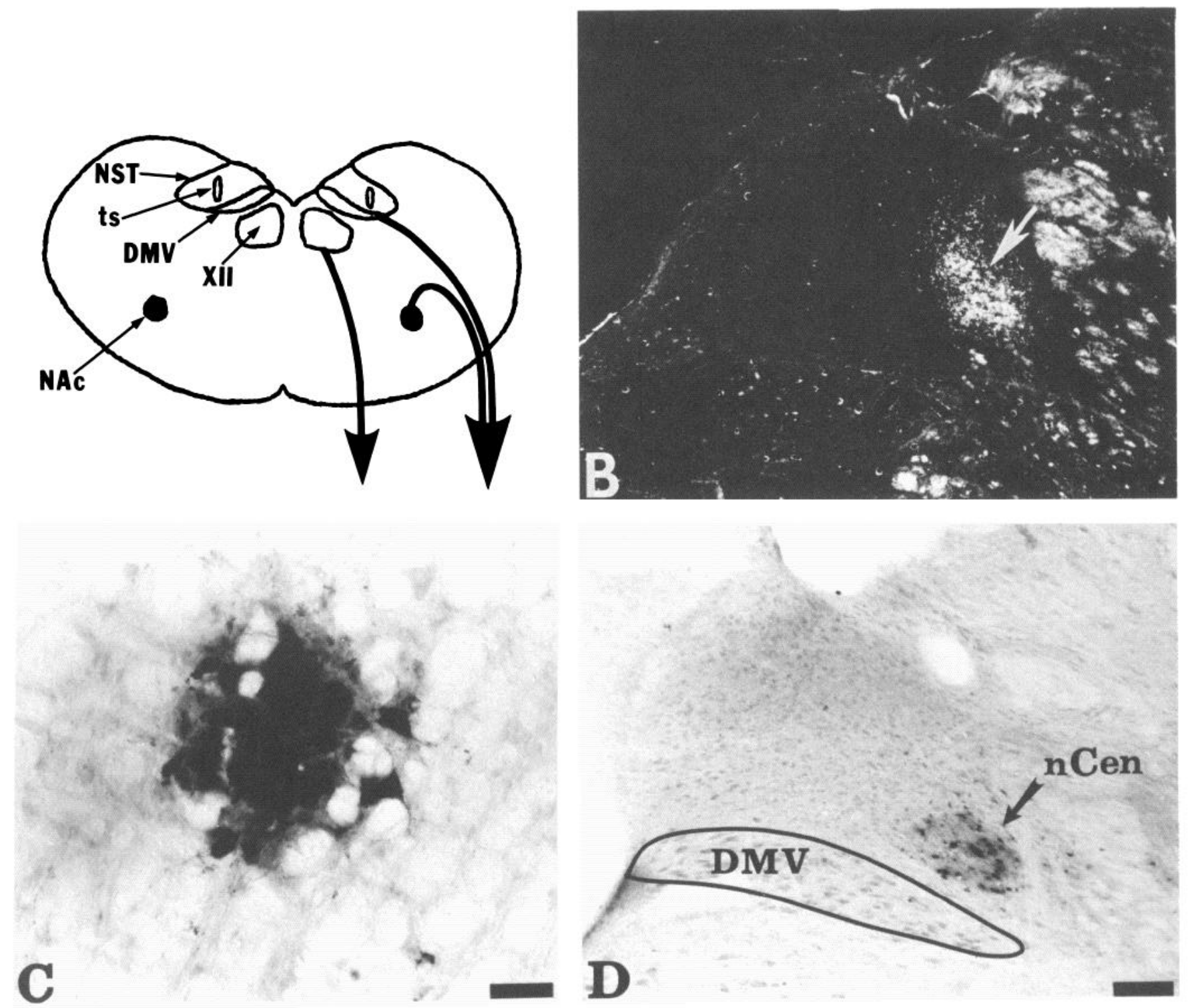

Figure 11. PRV injections of the esophagus result in retrograde transport of virions to motor neurons in the compact portion of the nucelus ambiguus $(C)$. Second-order neurons labeled in this experimental paradigm were confined to the subnucleus centralis of the NST $(n C E N ; D)$ in an area that is coextensive with the terminal arborization of sensory afferents labeled by anterograde transport of CT-HRP (dark-field photomicrograph in $B$ ). Scale bar, $365 \mu \mathrm{m}$ in $B$ and $D$; for $C, 150 \mu \mathrm{m}$.

rons was well advanced in the NST. By contrast, only scattered PRV-containing neurons were present in the entire diencephalon (hypothalamus and thalamus) as long as $57 \mathrm{hr}$ postinjection (Fig. 14).

\section{Discussion}

These data demonstrate that PRV is taken up by peripheral axons and transported retrogradely to motor neuron perikarya in the brain stem. Motor neuron labeling is entirely dependent on the site of injection and produces a projection-specific pattern of viral replication consistent with previous tract-tracing studies which mapped the localization of brain-stem motor neurons innervating the tongue (Hudoverning, 1907; Stuurman, 1916), stomach (Leslie et al., 1982; Shapiro and Miselis, 1985b), and esophagus (Bieger and Hopkins, 1987; Altschuler et al., 1989). The data also suggest that the virus passes transneuronally to infect neurons in synaptic contact with the afflicted primary motor neurons. The distribution of immunoreactive secondorder neurons is also dependent upon the site of injection and supports the findings of recent investigations which have mapped brain-stem projections to each of these motor nuclei (Lindvall and Björklund, 1978; Steinbush, 1981; Maley and Elde, 1982; Borke et al., 1983; Aldes and Boone, 1985; Borke and Nau, 1987; Sawchenko et al., 1987; Ugolini et al., 1987; Cunningham and Sawchenko, 1989). Finally, the demonstration of PRV transport through retinal axons to neurons in central visual targets indicates that the virus is also capable of anterograde transneuronal transport. Nevertheless, it is clear that the rate of anterograde transport is much slower than retrograde transport of the virus in the same animal. Collectively, these findings suggest that passage of PRV through the CNS occurs by specific transneuronal events rather than indiscriminate uptake of virions released into the extracellular space. 

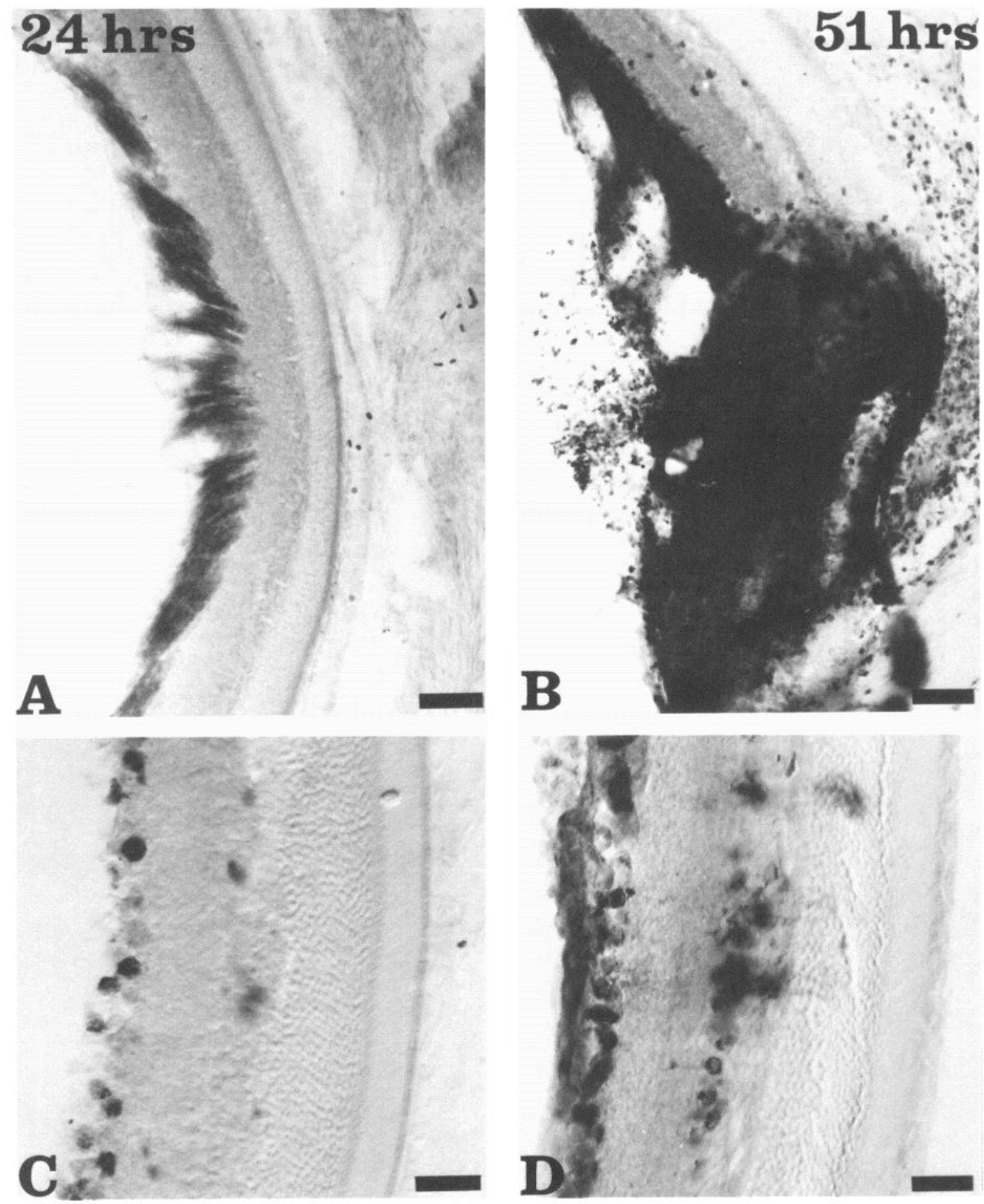

Figure 12. PRV injection of the vitreous body of the eye resulted in uptake of the virus into ganglion cells of the retina and anterograde transport into optic axons. $A, \mathrm{PRV}$-immunoreactive axons converging upon the papilla $24 \mathrm{hr}$ postinjection; at $51 \mathrm{hr}$, optic fibers in this same region exhibit dense immunoreactivity and viral-induced neuropathology extends through the retina $(B)$. With increasing survival, virions pass through the ganglion cells into the inner nuclear layers of the retina $(C$ and $D)$. Scale bars for $A$ and $B, 365 \mu \mathrm{m}$; for $C$ and $D, 150 \mu \mathrm{m}$.

\section{Specificity}

It is apparent from this and previous investigations (Kristensson, 1970; Cook and Stevens, 1973; McCracken et al., 1973; Field and Hill, 1975; Bak et al., 1977, 1978; Dolivo et al., 1978) that a number of neurotropic herpesviruses are internalized by axon terminals and transported retrogradely to the cell bodies of origin. Our data also support studies which have shown anterograde viral transport (Kristensson et al., 1978; Kucera et al., 1985 ) and those that have demonstrated transneuronal passage of virions through synaptically linked populations of neurons following peripheral or central injection of HSV-1 (Neeley et 

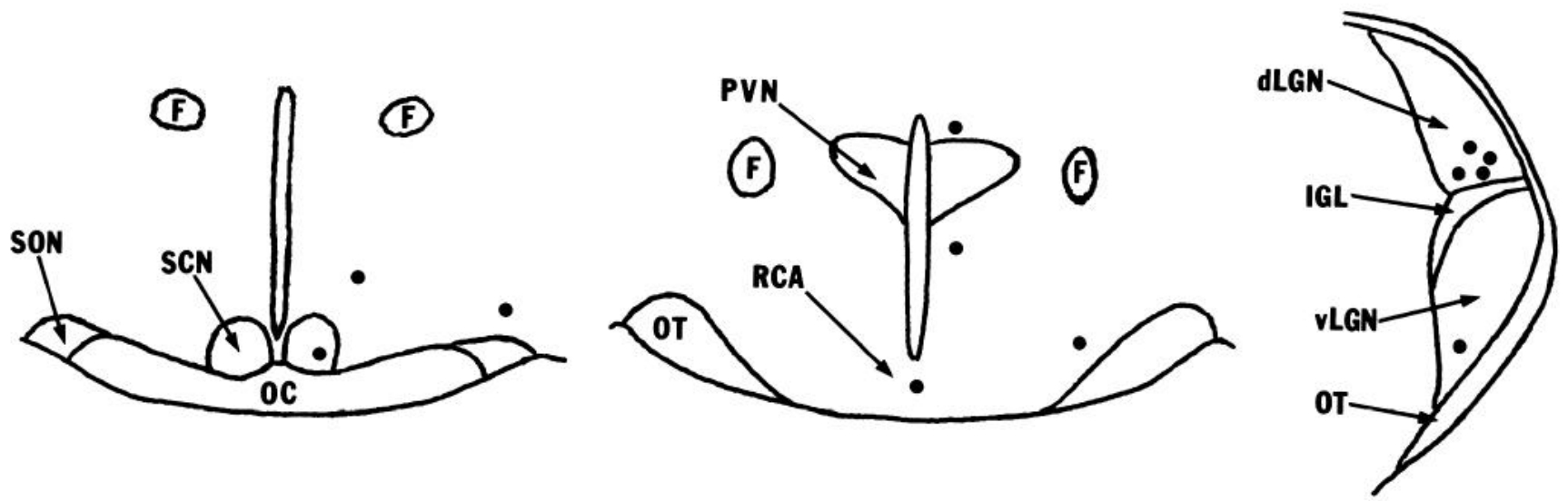

\section{SCN}
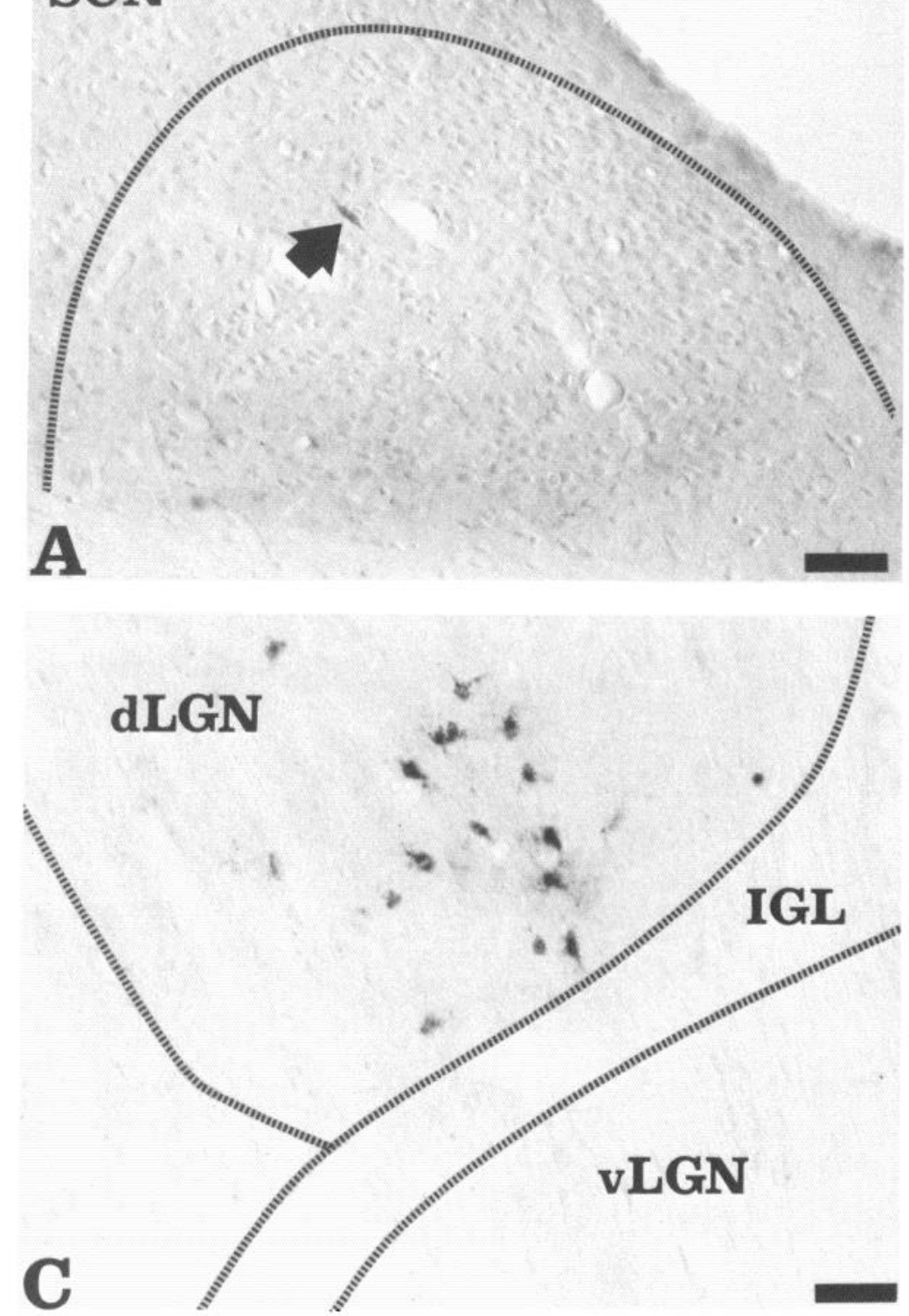

\section{LHA}
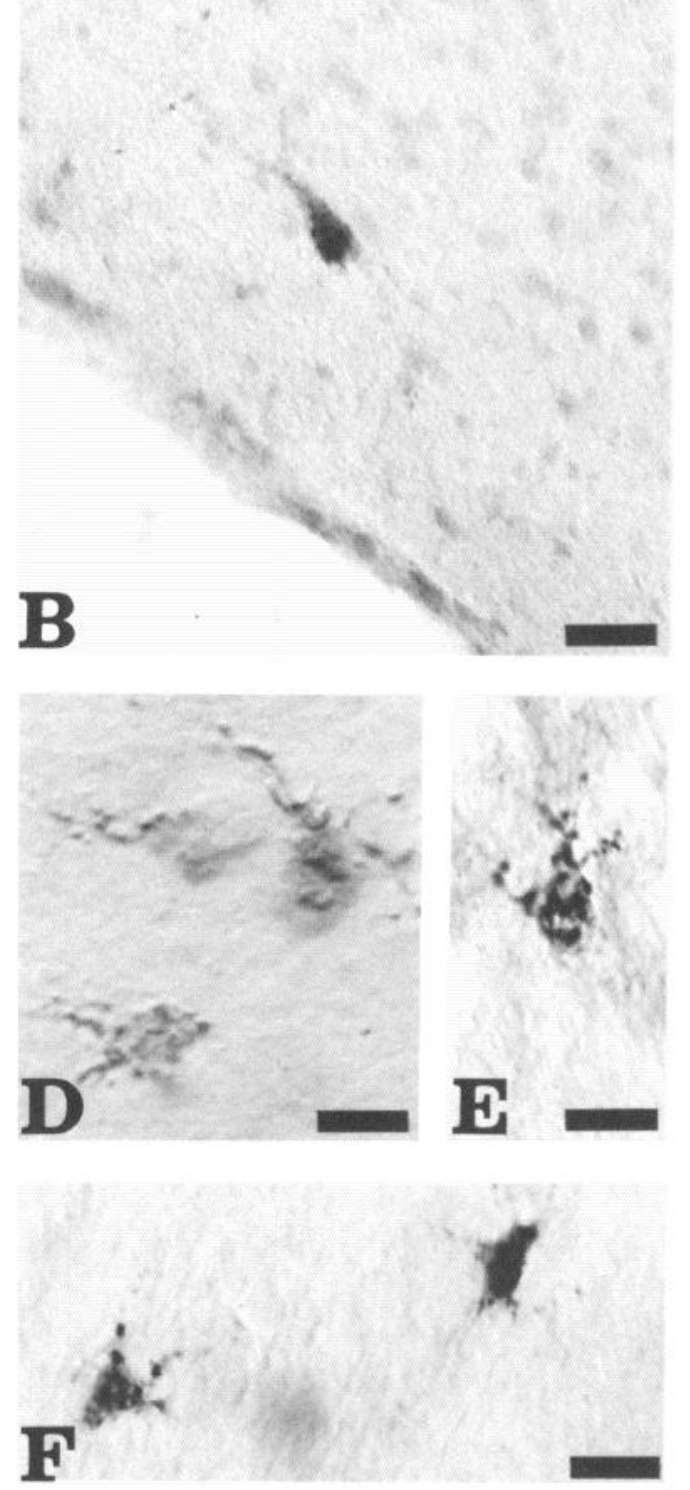

Figure 13. Distribution of PRV-immunoreactive neurons in the diencephalon $57 \mathrm{hr}$ following injection of the eye. Filled circles in the schematic diagrams illustrate the general pattern of cellular labeling. Scattered immunoreactive neurons were observed in the suprachiasmatic nuclei ( $S C N$; $A)$, the anterior hypothalamic and retrochiasmatic $(R C A)$ areas, the lateral hypothalamic area $(L H A ; B)$, and the dorsal and ventral subdivisions of the lateral geniculate complex. PRV immunoreactivity in the dLGN reflected progressive passage of virus from retinal axons into geniculate neurons; PRV-immunoreactive axons often surrounded immunonegative ( $D$ and $E$ ), as well as immunopositive $(F)$ neurons. Scale bar in $A$, 125 $\mu \mathrm{m}$; in $B$ and $D-F, 30 \mu \mathrm{m}$; in $C, 150 \mu \mathrm{m}$. 
al., 1985; Ugolini et al., 1987, 1989; Norgren and Lehman, 1989) and PRV (Martin and Dolivo, 1983; Rouiller et al., 1989; Strack et al., 1989). A remarkable feature common to all of these studies is the apparent specificity with which virions pass through the nervous system, especially when one considers the fact that the integrity of neurons in advanced stages of infection is known to be compromised (Martin and Dolivo, 1983; Ugolini et al., 1987; present investigation). Nevertheless, many of the above studies have provided convincing demonstrations of viral transport through defined neural circuits in a manner that suggests specific, transsynaptic passage of virions. Our findings in 4 different systems provide strong support for this conclusion and also offer insights into the means through which this specificity is achieved.

The most obvious reflection of the specificity of viral uptake and transport observed in our investigation is the discrete and reproducible localization of PRV-immunoreactive neurons in each experimental paradigm. The functional distribution of motor neurons in each of the systems examined in our analysis has been well characterized with conventional neuroanatomical tracers, and comparison of this labeling with that observed following PRV injection provides a fairly rigorous test of the specificity of PRV uptake and transport. For example, previous studies have shown that the principal innervation of the ventral stomach musculature is derived from motor neurons in the left DMV, with only a slight contribution from the right DMV (Leslie et al., 1982; Shapiro and Miselis, 1985b). In addition, motor neurons in the lateral pole of each DMV project to the cecum but do not contribute to the innervation of the stomach (Shapiro and Miselis, 1985b; Altschuler et al., 1989; Ferenci et al., 1989). The distribution of PRV-containing motor neurons demonstrated in our analysis following PRV injection of the ventral stomach was entirely consistent with this distribution; large numbers of immunoreactive neurons were present in the left DMV, scattered labeled neurons were present in the right DMV, and neither motor nucleus contained labeled neurons at its lateral pole. Similar specificity was apparent in the labeling of hypoglossal motor neurons following PRV injections of the tongue. Borke and Nau (1987) demonstrated segregation of neurons innervating protruder and retractor muscles of the tongue in the ventral and dorsal hypoglossal nucleus, respectively. The distribution of labeled neurons following either PRV or CTHRP injection supports this functional segregation of neurons. In both instances, labeled motor neurons were concentrated in the ventral half of the hypoglossal nucleus on the side of the brain stem ipsilateral to the site of injection. This is not surprising for the CT-HRP data, since the tracer was injected ipsilaterally into the genioglossis muscle. However, PRV was simply injected into the ventrolateral tongue musculature, and the resulting segregation of viral-immunoreactive neurons emphasizes the specificity of viral uptake and transport.

Further evidence of this specificity is apparent in a comparison of the motor neurons labeled by virus injected into the stomach and esophagus. These portions of the gastrointestinal tract are innervated by different motor neuron pools, but their fibers travel in the same nerve. In addition, both areas were injected in close proximity to the gastroesophageal junction in order to provide the most rigorous test of the extent of PRV diffusion. Under these circumstances, signifiant diffusion of virus from either site of injection would result in uptake and transport of the virus by motor neurons in both the DMV (stomach) and nucleus ambiguus (esophagus). Similarly, nonspecific

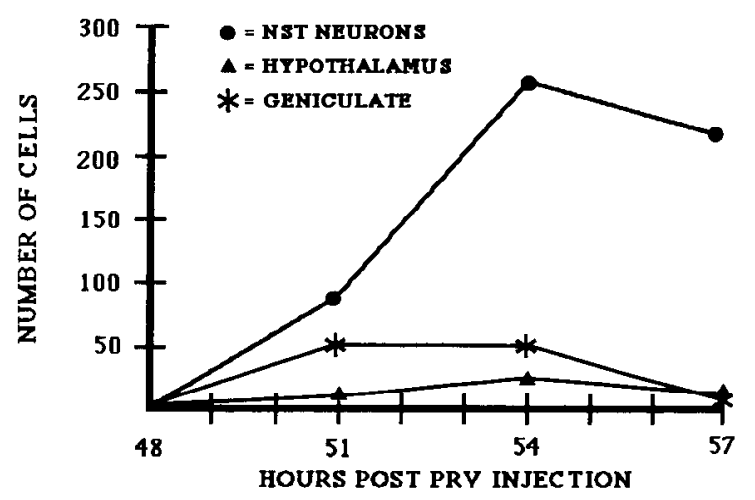

Figure 14. Number of neurons in the diencephalon labeled via anterograde transport of PRV from the eye compared to the number of PRVimmunoreactive second-order neurons of the NST of the same animal. The number of first-order neurons labeled by retrograde transport of PRV to the brain stem in the same population of animals is indicated in Figures 8 and 9. The data clearly indicate that anterograde transneuronal transport of PRV from the eye occurs at a much slower rate than retrograde transport from the stomach.

contamination of uninfected axons in the vagus nerve would be reflected in PRV labeling of motor neurons throughout the DMV (including those in the lateral pole which innervate the cecum) as well as in the nucleus ambiguus. Nevertheless, with the exception of one animal which was injected at the gastroesophageal junction and exhibited labeling of motor neurons in both the DMV and nucleus ambiguus, PRV was strictly confined to motor neurons of either the DMV or nucleus ambiguus in a pattern that was consistent with the site of injection. In addition, there was no evidence of retrograde transport of virions to motor neurons of the nucleus ambiguus in 2 cases in which PRV injections were made into the esophageal submucosa rather than the musculature. Finally, the possibility that some of the observed labeling may have been due to transport of PRV through the spinal cord in a manner similar to that reported by Strack and collaborators (1989) was precluded by the absence of brainstem labeling in response to cervical vagotomy. Collectively, these observations support the initial findings of Field and Hill (1975), which demonstrated that, while PRV replicates at the site of inoculation, its pronounced affinity for neuronal processes significantly reduces virus diffusion from the site of injection.

The only central labeling in the brain stem not attributable to retrograde, transneuronal passage of PRV was the immunoreactivity in glial cells. Immunoreactive astroglia were observed in the immediate vicinity of infected motor neurons and throughout the course of their efferent axons in the ventrolateral tegmentum. However, neuronal labeling always preceded the appearance of PRV-containing glia and the distribution of immunoreactive glia was restricted to sites of neuronal infection. A similar distribution of infected glia was seen in relation to brainstem neurons and axons in response to peripheral injection of HSV-1 into either the hypoglossal, median, or ulnar nerves (Ugolini et al., 1987, 1989). However, the glial reaction demonstrated at the motor rootlets in those studies was far more extensive than that observed following PRV injection (Martin and Dolivo, 1983; present investigation) and, at least with respect to the injections of the hypoglossal nerve (Ugolini et al., 1987), appeared to contribute to nonspecific labeling of neurons in the immediate vicinity of the infected motor rootlets and axons. Although these differences may be a simple reflection of 
the use of 2 different herpesviruses (HSV-1 vs PRV), they may also be explained by differences in the experimental protocols. Ugolini and colleagues $(1987,1989)$ injected HSV-1 directly into peripheral nerves, whereas Martin and Dolivo (1983) injected PRV into the masseter muscle, and we injected aliquots of PRV into muscles of the tonguc. esophagus, and stomach. The concentration of virions injected per animal did not differ significantly among the studies, but one would expect that nerve injection would lead to higher intraneuronal concentration of virions than would be achieved with muscle injections. Furthermore, the majority of animals in the Ugolini investigation (1987) were examined 72-144 hr postinjection, while our experimental analysis only exceeded $72 \mathrm{hr}$ in one case ( $74 \mathrm{hr}$ ) and Martin and Dolivo (1983) examined PRV localization 24 and $38 \mathrm{hr}$ following injection. Consequently, the discrete glial labeling and the apparent absence of nonspecific neuronal labeling observed in this and other investigations using PRV (Dolivo et al., 1978; Martin and Dolivo, 1983; Strack et al., 1989) indicate that longer postinjection intervals and/or higher intracellular concentrations of virus resulting from nerve injections may explain the pronounced glial labeling at motor rootlets and the occasional inappropriate neuronal labeling that has been observed in HSV-injected animals (Ugolini et al., 1987).

Data from this and other investigations indicate that the glial response to virus invasion of the nervous system contributes to the specific transport of virions between neurons. Numerous studies have shown that uptake and replication of herpesviruses ultimately leads to degeneration of infected neurons (Kristensson, 1970; Cook and Stevens, 1973; Kristensson et al., 1974, 1982; Bak et al., 1978; Dolivo et al., 1978; Martin and Dolivo, 1983; Openshaw and Ellis, 1983; Lycke et al., 1988). A natural consequence of this degeneration is a loss of cellular integrity with the resultant release of virions from the neuron. It is also well established that glial cells and processes undergo a characteristic hyperplasia in response to neuronal damage. In the current analysis, the appearance of immunoreactive astroglia always followed neuronal infection, and immunoreactive astroglia were intimately associated with PRV-containing neurons. In addition, we have recently extended our analysis to the electron microscopic level (Enquist et al., 1989; Rinaman et al., $1989 \mathrm{~b}$ ) and find that the reactive gliosis resulting from PRV infection of neurons effectively isolates PRV-infected somata and processes and thereby presents a formidable barrier to nonspecific diffusion of virions through the extracellular compartment. Evidence that this glial barrier is effective in restricting nonspecific spread of virions is apparent in examining the pattern of viral labeling along infected motor axons in the present investigation. These axons, although heavily invested with immunoreactive astroglia throughout their course, were never associated with immunoreactive neurons in the immediately adjacent brain-stem tegmentum. In addition, Vahlne and collaborators $(1978,1980)$ have demonstrated that glial cells have a high affinity for herpesviruses. Collectively, these factors argue convincingly for the conclusion that reactive gliosis contributes to specific transneuronal passage of virions through synaptically linked circuits by restricting nonspecific diffusion of virions.

\section{Transncuronal viral transport}

The unique pattern of cellular labeling observed in this and other investigations (Kristensson et al., 1974, 1978, 1982; Martin and Dolivo, 1983; Ugolini et al., 1987, 1989; Rouiller et al., 1989;
Strack et al., 1989) strongly suggests a specific transsynaptic passage of virus rather than indiscriminate neuronal labeling resulting from release of the virus into the extracellular space. I his interpretation is also supported by the fact that the projection systems revealed in each of these investigations involve circuitry composed of functionally related cell groups which, in many instances, have been previously demonstrated with conventional neuroanatomical tracers. Nevertheless, none of these observations establish an absolute synaptic connection among the cells in question, and, although not supported by our ultrastructural findings (Enquist et al., 1989; Rinaman et al., 1989b), it is still possible that the second-and third-order neuron labeling identified with herpesviruses is the result of virion uptake from the extracellular space. Resolution of this question is in large part dependent upon defining the means through which virions are released from infected neurons. It is clear that the later stage of infection are characterized by lysis of the cell, but there is very little information on viral transport and release during the initial stages of infection. A clear understanding of viral replication, assembly, and relcase during this carly time period is necessary, since it is quite conceivable that the first transneuronal passage of the virus precedes viral induced cellular necrosis.

A number of studies have employed transmission electron microscopy to examine neurotropic properties of PRV and HSV-I (Kristensson et al., 1974: Miyamoto and Morgan. 1974: Dolivo et al., 1978; Martin and Dolivo, 1983; Lycke et al., 1984, 1988). Ultrastructural analysis of HSV-1 infected human embryonic dorsal root ganglion cells in vitro (Lycke ct al.. 1988) has provided convincing evidence that membrane-limited cytoplasmic vesicles are instrumental in mediating both transport and release of virions. Under these circumstances, virions are released into the media via exocytosis following fusion of the cytoplasmic vesicle with the neuronal plasma membrane. It remains to be determined if this process of exocytosis is selective for particular portions of the plasma membrane and whether it can be generalized to the behavior of herpesviruses in vivo. Fine structural analyses of HSV-2 (Kristensson et al., 1974) and PRV (Dolivo et al., 1978; Martin and Dolivo, 1983) infected central neurons in vivo have provided insight into mechanisms of virion transport, replication, and assembly, but have proved inconclusive in determining the mechanisms of transneuronal passage of virions. Our own ultrastructural analysis (Enquist et al., 1989; Rinaman et al., 1989b) of transneuronal passage of PRV through hypoglossal and vagal circuits indicates that virions have a preferential affinity for the postsynaptic membrane at sites of afferent synaptic contact. These observations suggest that herpesviruses travel through the nervous system via synaptically linked circuits.

\section{Anterograde versus retrograde transport}

An important fact that must be taken into consideration in evaluating the source of PRV in second-order neuron populations is the terminal arborization of sensory afferents which arise in the gastrointestinal tract and terminate in the brain stem. Sensory afferents arising from both the esophagus and stomach terminate in very discrete areas of the brain stem which are in large part coextensive with the distribution of the second-order neuron populations revealed by PRV injections in the present study (Shapiro and Miselis, 1985b; Altschuler et al., 1989; Rinaman et al., 1989a). It is therefore possible that the second-order 
neuron labeling is due to anterograde, transganglionic transport of the virus through the sensory afferents into these cell populations. Although we cannot definitively exclude this possibility, several observations from this and other investigations make it unlikely. Our best evidence that the second-order neuron populations were actually infected via retrograde transncuronal transport was derived from experiments in which the same animal received virus injections in the stomach and both eyes. These experiments demonstrated anterograde, transneuronal transport of PRV into selected groups of retinal recipient neurons in areas known to receive retinal innervation. However, the rate at which this transport occurred was far slower than retrograde transport of the PRV in gastrointestinal circuitry of the same animal, and the number of immunoreactive neurons in retinal recipient areas of the diencephalon was a very small fraction of the total number of neurons that are known to receive retinal input. For example, a substantial number of the estimated 10,000 neurons in each SCN are known to receive a dense retinal innervation (Hendrickson et al., 1972; Moore and Lenn, 1972; Güldner, 1978a, b). Nevertheless, only scattered PRVcontaining neurons $(2-10 / \mathrm{SCN})$ were evident throughout the rostrocaudal extent of the SCN at survival times as long as 57 hr following injection of both eyes. Similarly, thousands of neurons in the lateral geniculate body receive direct retinal innervation, but we never observed more than 50 PRV-labeled neurons at any survival time. These observations stand in marked contrast to the large number of primary motor neurons (average of 1200) and second-order neurons in the NST (approximately 300 ) that were observed in the brain stem of the same animals and the fact that sensory afferents and astrocytes in the tractus solitarius did not exhibit PRV immunoreactivity. I Jgolini and collaborators (1989) noted a similar delay in anterograde transport through sensory fibers of the dorsal root ganglia following injection of the median and ulnar nerves with HSV-1. All of these findings are consistent with retrograde transneuronal transport of the virus to second-order neurons, but they do not exclude the possibility that these cells were infected by low levels of the virus in the sensory afferents that were not detected by our antisera.

\section{Functional considerations}

\section{Gastrointestinal circuitry}

The results of the PRV tracing studies confirm and extend prior observations on brain-stem sensory and motor viscerotopic organization. The DMV is longitudinally organized into medial and lateral columns, with the medial columns being most prominent (Fox and Powley, 1985; Norgren and Smith, 1988). In turn, the influence of various regions of the forebrain upon vagal autonomic function (i.e., cardiovascular regulation) has been established through identification of descending projections to neurons in the vagal complex (see Schwaber, 1986, and Sawchenko et al., 1987, for reviews). Gastric motor neurons have the most extensive anteroposterior distribution in the medial columns and far outnumber the medial column neurons projecting to the heart, liver, pancreas, and upper small intestine (Leslie et al., 1982; Shapiro and Miselis, 1985b; Rinaman and Miselis, 1987; Ferenci et al., 1989). The lateral columns are filled by motor neurons projecting to the cecum, to portions of the lower small intestine, and to the upper colon (Ferenci et al., 1989). Dendrites of DMV motor neurons arborize extensively within the DMV, passing both mediolaterally and anteropos- teriorly. Motor neuronal dendrites also leave the confines of the DMV and extend dorsally into the overlying NST (Shapiro and Miselis, 1985b; Armstrong et al., 1988), where gastric motor neuronal dendrites receive direct gastric sensory innervation (Rinaman et al., 1989a). The alimentary sensory terminal fields are organized anteroposteriorly in the NST (Altschuler et al., 1989) such that the central sensory representation of individual viscera tends to overlie certain motor neuronal pools in the DMV, perhaps permissive for visceral sensorimotor interaction.

The close proximity of the NST to the DMV has made it difficult to determine the distribution of NST neurons innervating the DMV, as tracer injection into one nucleus invariably diffuses into the other. In addition, the fact that vagal motorneurons are not confined to the DMV but have dendrites entering the NST further complicates anatomical analysis of connections between these 2 nuclei. The situation is less complicated for examining connections between the NST and the more distant nucleus ambiguus. By using central tracer injections, Cunningham and Sawchenko (1989) demonstrated a partly somatostatinergic projection from the NST to the nucleus ambiguus, probably subserving esophageal reflex motility. In their study, retrograde neuronal labeling in the NST was concentrated in the subnucleus centralis following tracer injection into the rostral part of the nucleus ambiguus, but labeled neurons were also present in surrounding regions of the medial and lateral NST. These results are not surprising, as tracer injected into the region of the rostral nucleus ambiguus will be picked up by nerve terminals not only in the compact formation of the nucleus ambiguus (site of esophagcal motor ncurons), but also by those in the semicompact and loose formations of the nucleus which contain cardiac, pulmonary, laryngeal, and pharyngeal motor neurons (Bieger and Hopkins, 1987). The present viral tracing work confirms the NST-nucleus ambiguus projection described by Cunningham and Sawchenko (1989). The unique contribution of the viral transport, however, is that it identifies a discrete subpopulation of these NST-nucleus ambiguus projection neurons, those of the subnucleus centralis, which are presynaptic to motor neurons innervating the subdiaphragmatic esophagus.

The pattern of second-order neuron labeling observed following stomach injections conforms to the pattern of dendritic penetration of the NST by gastric motor neurons. PRV-labeled gastric pre-motor neurons are distributed over a larger area of the medial NST than is gastric afferent input, as the latter is largely confined to the subnucleus gelatinosus of the NST (Shapiro and Miselis, 1985b; Altschuler et al., 1989; Rinaman et al., 1989a). The location of gastric pre-motor neurons revealed by the present viral tracing technique is consistent with the location of physiologically identified, gastric-related NST neurons, some of which also respond to stimulation of higher brain centers (Harding and Leek, 1973; Barber and Burks, 1983; Ewart and Wingate, 1983; Nishimura and Oomura, 1987). The presence of PRV-labeled neurons in the nuclei raphe obscurus and pallidus following stomach injection is also consistent with a known raphe-DMV/NST projection involved in gastric modulation (McCann et al., 1989), which recent evidence suggests is at least partially TRH-ergic (Palkovits et al., 1986; Lynn et al., 1989). It is likely that retrograde transneuronal viral transport from infected gastric motor neurons to these raphe neurons is at least partially mediated via the TRH-ergic raphe-DMV/NST projection, as a portion of the TRH-immunoreactive terminals in the DMV/NST synapse directly on the dendrites of gastric vagal motor neurons (Rinaman and Miselis, 1990). 


\section{Neurotropic aspects of PRV}

The circuit-specific patterns of PRV invasion of the nervous system observed in this and other studies (McCracken et al., 1973; Dolivo et al., 1978, 1979; Martin and Dolivo, 1983; Strack et al., 1989) also provide clear opportunities for examining the factors directing uptake, replication, assembly, and transport of virions through neurons of the mammalian brain. Two important questions, for example, focus upon the means through which virus is transported within neurons as well as the mechanisms which direct transsynaptic passage of virions. Each of these questions is important not only from the standpoint of understanding the mechanisms of neurotropic viral interactions, but also in identifying strategies for therapeutic intervention of viral infections and determining the efficacy of using herpesviruses as vectors for introducing foreign genes into the nervous system (Breakefield and Geller, 1987; Geller and Breakefield, 1988). We have begun to approach some of these questions by extending our light microscopic immunohistochemical analysis to the ultrastructural level and by examining the behavior of well-defined PRV mutants in the experimental paradigms established in the present report. The data derived from the present analysis has provided us with an extremely valuable foundation for evaluating the effects of viral mutations upon neurovirulence and transport of virions. Our preliminary results (Miselis et al., 1989) and those of Strack and collaborators (1989) indicate that at least one attenuated strain of PRV remains neurotropic but is less virulent. Continued efforts in this regard should prove useful in identifying those mechanisms which regulate viral transport and replication within the nervous system.

\section{References}

Aldes LD, Boone TB (1985) Organization of projections from the principal sensory trigeminal nucleus to the hypoglossal nucleus in the rat: an experimental light and electron microscopic study with axonal tracer techniques. Exp Brain Res 59:16-29.

Altschuler SM, Bao X, Bieger D, Hopkins DA, Miselis RR (1989) Viscerotopic representation of the upper alimentary tract in the rat: sensory ganglia and nuclei of the solitary and spinal trigeminal tracts. J Comp Neurol 283:248-268.

Armstrong DM, Rotler A, Hersh LB, Pickel VM (1988) Localization of choline acetyltransferase in perikarya and dendrites within the nuclei of the solitary tracts. J Neurosci Res 20:279-290.

Bak IJ, Markham, CH, Cook ML, Stevens JG (1977) Intraaxonal transport of herpes simplex virus in the rat central nervous system. Brain Res 136:415-429.

Bak IJ, Markham CH, Cook ML, Stevens JG (1978) Ultrastructural and immunoperoxidase study of striatonigral neurons by means of retrograde axonal transport of herpes simplex virus. Brain Res 143: 361-368.

Barber WD, Burks TF (1983) Brain stem response to phasic gastric distension. Am J Physiol 245:G242-G248.

Baringer JR, Griffith JF (1970) Experimental herpes simplex encephalitis: early neuropathologic changes. J Neuropathol Exp Neurol 29: $89-104$.

Bieger D, Hopkins DA (1987) Viscerotopic representation of the upper alimentary tract in the medulla oblongata in the rat: the nucleus ambiguus. J Comp Neurol 262:546-562.

Borke RC, Nau ME (1987) The ultrastructural morphology and distribution of trigemino-hypoglossal connections labeled with horseradish peroxidase. Brain Res 422:235-241.

Borke RC, Nau ME, Ringler RL Jr (1983) Brainstem afferents of hypoglossal neurons in the rat. Brain Res 269:47-55.

Breakefield XO, Geller AI (1987) Gene transfer in the nervous system. Mol Neurobiol 1:339-371.

Card JP, Brecha NC, Karten HJ, Moore RY (1981) Immunocytochemical localization of vasoactive intestinal polypeptide-containing cells and processes in the suprachiasmatic nucleus of the rat: light and electron microscopic analysis. J Neurosci 1:1289-1303.

Cook ML, Stevens JG (1973) Pathogenesis of herpetic neuritis and ganglionitis in mice-evidence for intra-axonal transport of infection. Infect Immunol 7:272-288.

Cunningham ET Jr, Sawchenko PE (1989) A circumscribcd projection from the nucleus of the solitary tract to the nucleus ambiguus in the rat: anatomical evidence for somatostatin-28-immunoreactive neurons subserving reflex control of esophageal motility. J Neurosci 9: 1668-1682.

Dolivo M, Beretta E, Bonifas V, Foroglou C (1978) Ultrastructure and function in sympathetic ganglia isolated from rats infected with pseudorabies virus. Brain Res 140:111-123.

Dolivo M, Honegger P, George C, Kiraly M, Bommeli W (1979) Enzymatic activity, ultrastructure and function in ganglia infected with a neurotropic virus. Prog Brain Res 51:51-57.

Enquist I, Rinaman I, Whealy M, Robbins A, Card JP (1989) Uptake, replication and trans-neuronal transport of pseudorabies virus within neuronal circuits influencing gastric function. In: 14th Annual herpesvirus workshop, Denmark, p 52

Ewart WR, Wingate DL (1983) Central representation and opioid modulation of gastric mechanoreceptor activity in the rat. Am J Physiol 244:G27-G32.

Ferenci DA, Altschuler SM, Miselis RR (1989) Representation of the rat cecum in the lateral dorsal motor nucleus (DMN): further evidence for selective vagal control of motility. Gastroenterology 96:A148.

Field HJ, Hill TJ (1975) The pathogenesis of pseudorabies in mice: virus replication at the inoculation site and axonal uptake. J Gen Virol 26:145-148.

Fox EA, Powley TL (1985) Longitudinal columnar organization within the dorsal motor nucleus represents separate branches of the abdominal vagus. Brain Res 341:269-282.

Geller AI, Breakefield XO (1988) A defective HSV-1 vector expresses Escherichia coli $\beta$-galactosidase in cultured peripheral neurons. Science 241:1667-1669.

Goodpasture EW, Teague O (1923) Transmission of the virus of herpes fibrils along nerves in experimentally infected rabbits. J Med Res 44: 139-184.

Güldner F-H (1978a) Synapses of optic nerve afferents in the rat suprachiasmatic nucleus. 1. Identification, qualitative description, development and distribution. Cell Tissue Res 194:17-35.

Güldner F-H (1978b) Synapses of optic nerve afferents in the rat suprachiasmatic nucleus. Il. Structural variability as revealed by morphometric examination. Cell Tissue Res 194:37-54.

Harding R, Leek BF (1973) Central projections of gastric afferent vagal inputs. J Physiol (Lond) 228:73-90.

Hendrickson AE, Wagoner N, Cowan WM (1972) An autoradiographic and electron microscopic study of retinohypothalamic connections. Z Zellforsch 135:1-26.

Hsu SM, Raine L, Fanger H (1981) Use of avidin-biotin-peroxidase complex $(A B C)$ in immunoperoxidase techniques: a comparison between $\mathrm{ABC}$ and unlabeled antibody (PAP) procedures. J Histochem Cytochem 29:577-580.

Hudovernig C (1907) Beiträge zur mikroskopischen anatomie und zur localisationslehre einiger Gehirnnervenderne (Nervus Hypoglossus, Vagus und Facialis). J Psychol Neurol (Lpz) 9:137-164.

Johnson RF, Morin LP, Moore RY (1988) Retinohypothalamic projections in the hamster and rat demonstrated using cholera toxin. Brain Res 462:301-312.

Kristensson K (1970) Morphological studies of the neural spread of herpes simplex virus to the central nervous system. Acta Neuropathol 16:54-63.

Kristensson K, Ghetti B, Wisniewski HM (1974) Study on the propagation of herpes simplex virus (type 2) into the brain after intraocular injection. Brain Res 69:189-201.

Kristensson K, Vahlne A, Persson LA, Lycke E (1978) Neural spread of herpes simplex virus types 1 and 2 in mice after corneal or subcutaneous (footpad) inoculation. J Neurol Sci 35:331-340.

Kristensson K, Nennesmo I, Persson L, Lycke E (1982) Neuron to neuron transmission of herpes simplex virus. Transport of virus from skin to brainstem nuclei. J Neurol Sci 54:149-156.

Kucera P, Dolivo M, Coulon P, Flamand A (1985) Pathways of early propagation of virulent and avirulent rabies strains from the eye to the brain. J Virol 55:158-162.

Leslie RA, Gwyn DG, Hopkins DA (1982) The central distribution 
of the cervical vagus nerve and gastric afferent and efferent projections in the rat. Brain Res Bull 8:37-43.

Levine JD, Weiss ML, Gosin D, Rosenwasser AM, Miselis RR (1986) $\mathrm{Re}$-examination of the retinohypothalamic projections of the rat using HRP conjugated to cholera toxin (CT-HRP). Soc Neurosci Abstr 12: 549.

Lindvall O, Björklund A (1978) Organization of catecholamine neurons in the rat central nervous system. In: Handbook of psychopharmacology, Vol 9 (Iverson LL, Iverson SD, Snyder SH, eds), pp 139-231. New York: Plenum.

Lycke E, Kristensson K, Svennerholm B, Vahlne A, Ziegler RJ (1984) Uptake and transport of herpes simplex virus in neurites of rat dorsal root ganglia cells in culture. J Gen Virol 65:55-64.

Lycke E, Hamark B, Johansson M, Krotochwil A, Lycke J, Svennerholm $B$ (1988) Herpes simplex virus infection of the human sensory neuron. An electron microscopic study. Arch Virol 101:87-104.

Lynn RB, Rinaman L, Miselis RR (1989) Distribution, connectivity, and origin of TRH-immunoreactive (TRH-I) fibers in the dorsal motor nucleus of the vagus and nucleus of the solitary tract (DMV/NST) in rat. Soc Neurosci Abstr 15:264.

Mai JK (1979) Distribution of retinal axons within the lateral hypothalamic area. Exp Brain Res 34:373-377.

Maley B, Elde R (1982) Immunohistochemical localization of putative neurotransmitters within the feline nucleus tractus solitarii. Neuroscience 7:2469-2490.

Martin X, Dolivo M (1983) Neuronal and transneuronal tracing in the trigeminal system of the rat using herpes virus suis. Brain Res 273:253-276.

McCann MJ, Hermann GE, Rogers RC (1989) Nucleus raphe obscurus (nRO) influences vagal control of gastric motility in rats. Brain Res 486:181-184.

McCracken RM, McFerran JB, Dow C (1973) The neural spread of pseudorabies virus in calves. J Gen Virol 20:17-28.

McFarland D (1989) Temporal development of the behavioral effects of herpes encephalitis in mice. Psychobiology 17:276-280.

McLean IW, Nakane PK (1974) Periodate-lysine-paraformaldehyde fixative. A new fixative for immunoelectron microscopy. J Histochem 22:1077-1083.

Mesulam M-M (1982) Principles of horseradish peroxidase neurochemistry and their applications for tracing neural pathways-axonal transport, enzyme histochemistry, and light microscopic analysis. In: Tracing neural connections with horseradish peroxidase (Mesulam M-M, ed), pp 1-151. New York: Wiley.

Miselis RR, Rogers WT, Schwaber J, Spyer M (1989) Localization of cardiomotor neurons in anesthetized rat; cholera toxin-HRP conjugate and pseudorabies virus. I Physiol (Lond) 416:631.

Miyamoto K, Morgan C (1974) Structure and development of viruses as observed in the electron microscope. XI. Entry and uncoating of herpes simplex virus. J Virol 8:910-918.

Moore RY, Lenn NJ (1972) A retinohypothalamic projection in the rat. J Comp Neurol 146:1-14.

Neeley SP, Cross AJ, Crow TJ, Johnson JA, Crow GR (1985) Ilerpes simplex virus encephalitis: neuroanatomical and neurochemical selectivity. J Neurol Sci 71:325-337.

Nishimura H, Oomura Y (1987) Effects of hypothalamic stimulation of activity of dorsomedial medulla neurons that respond to subdiaphragmatic vagal stimulation. J Neurophysiol 58:655-675.

Norgren RB Jr, Lehman MN (1989) Retrograde transneuronal transport of Herpes simplex virus in the retina after injection in the superior colliculus, hypothalamus and optic chiasm. Brain Res 479:374-378.

Norgren R, Smith GP (1988) Central distribution of subdiaphragmatic vagal branches in the rat. J Comp Neurol 273:207-223.

Openshaw H, Ellis WG (1983) Herpes simplex virus infection of motor neurons: hypoglossal model. Infect Immunol 42:409-413.

Palkovits M, Mezey E, Eskay RL, Brownstein MJ (1986) Innervation of the nucleus of the solitary tract and the dorsal vagal nucleus by thyrotropin-releasing hormone-containing raphe neurons. Brain Res 373:246-251.

Pickard GE, Silverman A-J (1981) Direct retinal projections to the hypothalamus, periform cortex, and accessory optic nuclei in the golden hamster as demonstrated by a sensitive anterograde horseradish peroxidase technique. J Comp Neurol 196:155-172.

Riley JN, Card JP, Moore RY (1981) A retinal projection to the lateral hypothalamus in the rat. Cell Tissue Res 214:257-269.

Rinaman L, Miselis RR (1987) The organization of vagal innervation of rat pancreas using cholera toxin-horseradish peroxidase conjugate. J Autonom Nerv Syst 21:109-125.

Rinaman L, Miselis RR (1990) Thyrotropin-releasing hormone-immunoreactive nerve terminals synapse on the dendrites of gastric vagal motoneurons in rat. J Comp Neurol 294:235-251.

Rinaman L, Card JP, Schwaber JS, Miselis RR (1989a) Ultrastructural demonstration of a gastric monosynaptic vagal circuit in the nucleus of the solitary tract in rat. J Neurosci 9:1985-1996.

Rinaman L, Robbins A, Whealy M, Card JP, Enquist L (1989b) Uptake, replication and trans-synaptic passage of pseudorabies in brainstem circuits. Soc Neurosci Abstr 15:122.2.

Robbins AK, Whealey ME, Watson RJ, Enquist LW (1986) Pseudorabies virus gene encoding glycoprotein gIII is not essential for growth in tissue culture. J Virol 59:636-645.

Rouiller EM, Capt M, Dolivo M, De Ribaupierre F (1989) Neuronal organization of the stapedius reflex pathways in the rat: a retrograde HRP and viral transneuronal tracing study. Brain Res 476:21-28.

Ryan JP, Whealy ME, Robbins AK, Enquist LW (1987) Analysis of pseudorabies virus glycoprotein III localization and modification using novel, infectious viral mutants carrying unique EcoRI sites. J Virol 61: 2962-2972.

Sawchenko PE, Cunningham ET, Jr, Levin MC (1987) Anatomic and biochemical specificity in central anatomic pathways. In: Organization of the autonomic nervous system: central and peripheral mechanisms (Ciriello J, Calaresu FR, Renaud LP, Polosa C, eds), pp 267281. New York: AR Liss.

Schwaber JS (1986) Neuroanatomical substrates of cardiovascular and emotional-autonomic regulation. In: Central and peripheral mechanisms of cardiovascular regulation (Margo A, Osswald W, Reis D, Vanhoutte P, eds), pp 353-384. New York: Plenum.

Shapiro RE, Miselis RR (1985a) The central neural connections of the area postrema of the rat. J Comp Neurol 234:344-364.

Shapiro RE, Miselis RR (1985b) The central organization of the vagus nerve innervating the stomach of the rat. J Comp Neurol 238:473488.

Steinbush HM (1981) Distribution of serotonin immunoreactivity in the central nervous system of the rat. Cell bodies and terminals. Neuroscience 6:557-618.

Sternberger LA (1979) The unlabeled antibody peroxidase-antiperoxidase (PAP) method. In: Immunocytochemistry (Sternberger L, ed), pp 104-169. New York: Wiley.

Strack AM, Sawyer WB, Hughes JH, Platt KB, Loewy AD (1989) A general pattern of CNS innervation of the sympathetic outflow demonstrated by transneuronal pseudorabies viral infections. Brain Res 491:156-162.

Stroop WG, Baringer JR (1989) Herpes simplex virus infections of the nervous system. In: Clinical and molecular aspects of neurotropic virus infection (Gilden DH, Lipton HL, eds), pp 343-368. Boston: Kluwer Academic.

Stuurman FJ (1916) Die localization der zugenmuskeln im nucleus hypoglossi. Anat Anz 48:593-610.

Trojanowski JQ, Schmidt ML (1984) Interncuronal transfer of axonally transported proteins: studies with HRP and HRP conjugates of wheat germ agglutinin, cholera toxin and the $\beta$ subunit of cholera toxin. Brain Res 311:366-369.

Trojanowski JQ, Gonatas JO, Gonatas NK (1981) Conjugate of horseradish peroxidase (HRP) with cholera toxin and wheat germ agglutinin are superior to free HRP as orthogradely transported markers. Brain Res 223:381-385.

Trojanowski JQ, Gonatas JO, Gonatas NK (1982) Horseradish peroxidase (HRP) conjugates of cholera toxin and lectins are more sensitive retrogradely transported markers than free HRP. Brain Res 231:33-50.

Townsend JJ, Baringer JR (1978) Central nervous system susceptibility to herpes simplex infection. J Neuropathol Exp Neurol 37:255262.

Ugolini G, Kuypers HGJM, Simmons A (1987) Retrograde transneuronal transfer of Herpes simplex virus type 1 (HSV 1) from motoneurons. Brain Res 422:242-256.

Ugolini G, Kuypers HGJM, Strick PL (1989) Transneuronal transfer of herpes virus from peripheral nerves to cortex and brainstem. Science 243:89-91.

Vahlne A, Nystrom B, Sandberg M, Hamberger A, Lycke E (1978) Attachment of herpes simplex virus to neurons and glial cells. J Gen Virol 40:359-371. 
Vahlne A, Svennerholm B, Sandberg M, Hamberger A, Lycke E (1980) Differences in attachment between herpes simplex type 1 and type 2 viruses to neurons and glial cells. Infect Immunol 28:675-680.

Wildy $P$ (1967) The progression of herpes simplex virus to the central nervous sytem of the mouse. J Hyg Camb 65:173-192.
Wittmann G, Rziha H-J (1989) Aujeszky's disease (pseudorabies) in pigs. In: Herpesvirus diseases of cattle, horses and pigs (Wittmann $\mathrm{G}$, ed), pp 230-333. Boston: Kluwer Academic. 